\title{
Similarities between decapod and insect neuropeptidomes
}

Jan A Veenstra

Background. Neuropeptides are important regulators of physiological processes and behavior. Although they tend to be generally well conserved, recent results using trancriptome sequencing on decapod crustaceans give the impression of significant differences between species, raising the question whether such differences are real or artefacts.

Methods. The BLAST+ program was used to find short reads coding neuropeptides and neurohormons in publicly available short read archives. Such reads were then used to find similar reads in the same archives and the DNA assembly program Trinity was employed to construct contigs encoding the neuropeptide precursors as completely as possible.

Results. The seven decapod species analyzed in this fashion, the crabs Eriocheir sinensis, Carcinus maenas and Scylla paramamosain, the shrimp Litopenaeus vannamei, the lobster Homarus americanus, the fresh water prawn Macrobrachium rosenbergii and the crayfish Procambarus clarkii had remarkably similar neuropeptidomes. Although some neuropeptide precursors could not be assembled, in many cases individual reads pertaining to the missing precursors show unambiguously that these neuropeptides are present in these species. In other cases the tissues that express those neuropeptides were not used in the construction of the cDNA libraries. One novel neuropeptide was identified, elongated $\mathrm{PDH}$ (pigment dispersing hormone), a variation on PDH that has a two amino acid insertion in its core sequence. Hyrg is another peptide that is ubiquitously present in decapods and is likely a novel neuropeptide precursor.

Discussion. Many insect species have lost one or more neuropeptide genes, but apart from elongated PDH and hyrg all other decapod neuropeptides are present in at least some insect species and allatotropin is the only insect neuropeptide missing from decapods. This strong similarity between insect and decapod neuropeptidomes makes it possible to predict the receptors for decapod neuropeptides that have been deorphanized in insects. This includes the androgenic insulin-like peptide that seems to be homologous to drosophila insulin-like peptide 8. 
1

\section{Similarities between decapod and insect neuropeptidomes}

3

4

5 Jan A. Veenstra ${ }^{1}$

$6 \quad{ }^{1}$ INCIA, UMR 5287 CNRS, Université de Bordeaux, Pessac, France

7

8 Corresponding Author:

9 Jan Veenstra, INCIA UMR 5287 CNRS, Université de Bordeaux, allée Geoffroy St Hillaire, CS

10 50023, 33615 Pessac Cedex, France

11 Email address: jan.veenstra@u-bordeaux.fr

12

13

14 


\section{Abstract}

16 Background. Neuropeptides are important regulators of physiological processes and behavior.

17 Although they tend to be generally well conserved, recent results using trancriptome sequencing

18 on decapod crustaceans give the impression of significant differences between species, raising

19 the question whether such differences are real or artefacts.

20 Methods. The BLAST + program was used to find short reads coding neuropeptides and

21 neurohormones in publicly available short read archives. Such reads were then used to find

22 similar reads in the same archives and the DNA assembly program Trinity was employed to

23 construct contigs encoding the neuropeptide precursors as completely as possible.

24 Results. The seven decapod species analyzed in this fashion, the crabs Eriocheir sinensis,

25 Carcinus maenas and Scylla paramamosain, the shrimp Litopenaeus vannamei, the lobster

26 Homarus americanus, the fresh water prawn Macrobrachium rosenbergii and the crayfish

27 Procambarus clarkii had remarkably similar neuropeptidomes. Although some neuropeptide

28 precursors could not be assembled, in many cases individual reads pertaining to the missing 29 precursors show unambiguously that these neuropeptides are present in these species. In other cases the tissues that express those neuropeptides were not used in the construction of the cDNA

31 libraries. One novel neuropeptide was identified, elongated PDH (pigment dispersing hormone),

32 a variation on PDH that has a two amino acid insertion in its core sequence. Hyrg is another

33 peptide that is ubiquitously present in decapods and is likely a novel neuropeptide precursor.

34 Discussion. Many insect species have lost one or more neuropeptide genes, but apart from

35 elongated PDH and hyrg all other decapod neuropeptides are present in at least some insect species and allatotropin is the only insect neuropeptide missing from decapods. This strong similarity between insect and decapod neuropeptidomes makes it possible to predict the receptors for decapod neuropeptides that have been deorphanized in insects. This includes the androgenic insulin-like peptide that seems to be homologous to drosophila insulin-like peptide 8 . 
41

42

43

44

45

46

47

48

49

50

51

\section{Introduction}

Lobsters, crayfish, prawns, crabs and shrimps are all crustaceans belonging to the order of the decapods. Many of these species are part of the human diet, are sometimes a major source of protein and are often considered a delicacy. While some species are caught in the wild, others, e.g. the freshwater prawn Macrobrachium rosenbergii, are mainly obtained from commercially important cultures. Many of these species are also sufficiently large to allow physiological experiments that are more difficult to perform on smaller arthropods. For these reasons decapods probably constitute the second best studied group of arthropods after insects. Neuropeptides have also been extensively researched in decapods and several neuropeptides were initially identified in these crustaceans before they were found in other arthropods such as insects (e.g. Kegel et al., 1989; Stangier et al., 1987, 1992).

The sizes of their genomes tend to be large (e.g. Yu et al., 2015; Song et al., 2016) and so far no complete decapod genome is available. Initially sequences of crustacean neuropeptides were determined by classical peptide isolation and Edman degradation (e.g. Kegel et al., 1989; Stangier et al., 1987, 1992; Bungart et al., 1995; Duve et al., 1997), but in the last decade numerous decapod peptides have been sequenced by mass spetrometry (e.g. Dickinson et al., 2008, 2009a,b; Ma et al., 2008, 2009, 2010; Stemmler et al., 2007a,b, 2010). In the last two years identification of the decapod neuropeptidomes has further accelerated using next-generation sequencing methodology. As a consequence we now have fairly long lists of neuropeptides for several decapods. These include Sagmariasus verrauxi (Ventura et al., 2014), M. rosenbergii (Suwansa-Ard et al., 2015), Procambarus clarkii (Veenstra, 2015), Scylla paramamosain (Bao et al., 2015) and Homarus americanus (Christie et al, 2015), while for other decapods significant amounts of data are available to analyze their neuropeptidomes. This is for the example the case for Carcinus maenas, Litopenaeus vannamei and Eriocheir sinensis (Li et al., 2012; Ghaffari et al., 2014; Verbruggen et al., 2015; Xu et al., 2015). Some of the ESTs (expressed sequence tags) present in the publicly available databases have been summarized by Christie and his collaborators (Ma et al., 2009, 2010; Christie, 2014, 2016; Christie \& Chi, 2015).

I have previously used the published short read archives for P. clarkii to look for neuropeptide transcripts and could deduce complete or partial sequences for a surprisingly large number of neuropeptide precursors (Veenstra, 2015). When comparing the results obtained in 
72 this species, with the lists of neuropeptide transcripts from other decapods, differences appear.

73 While several neuropeptides are consistently found in all species, others are only identified in

74 75 76 77 78 79

80

81

82

83

84 85 86 87 88

89

90 some. The question is whether these differences are real or represent artefacts. For example, some peptides may not have been searched for in the assembled reads, or there were simply too few reads to allow assembly of a contig, while in other cases the tissue where the particular gene is predominantly expressed was perhaps not included in the analysis. I here try to answer these questions by reanalyzing published short sequence read archives for a number of decapods.

\section{Materials \& Methods}

DNA sequences

The following short read archives (SRAs) were downloaded from NCBI using the prefetch command from the SRA Toolkit (http://www.ncbi.nlm.nih.gov/books/NBK158900/) : for $C$. maenas: SRR1564428, SRR1572181, SRR1586326, SRR1589617, SRR1612556, SRR1632279, SRR1632285, SRR1632289, SRR1632290, SRR1632291, SRR1632292 and SRR1632293 (Verbruggen et al., 2015); for P. clarkii: SRR1144630, SRR1144631, SRR1265966, SRR1509456, SRR1509457, SRR1509458 and SRR870673 (Jiang et al., 2014; Tom et al., 2014; Shen et al., 2014; Manfrin et al., 2015); for M. rosenbergii: DRR023219, SRR1559288, SRR345608, SRR572725, DRR023253, SRR1653452, SRR345609, SRR896637, SRR1138560, SRR1653453, SRR345610, SRR896638, SRR1138561, SRR1653454, SRR345611, SRR896645, SRR1138562, SRR567391, SRR896646, SRR1138563, SRR572719, SRR896647, SRR1138564, SRR572720, SRR896649, SRR1138565, SRR572721, SRR896650, SRR1138572, SRR2082768, SRR572722, SRR896651, SRR1138573, SRR2082769, SRR572723, SRR1559287, SRR2082770, SRR572724 (Jung et al., 2011; Ventura et al., 2013; Suwansa-Ard et al., 2015); for S. paramamosain: SRR1310332, SRR1310333, SRR1205999, SRR3086589, SRR834579, SRR1206015, SRR3086590, SRR834580, SRR1310331 and SRR3086592 (Gao et al., 2014; Ma et al., 2014; Bao et al., 2015); for L. vanamei: SRR1037362, SRR1407789, SRR1460505, SRR1952625, SRR2103853, SRR2103860, SRR2895158, SRR1037363, SRR1104812, SRR1407790, SRR1609917, SRR2060962, SRR2103854, SRR2103861, SRR346404, SRR1037364, SRR1105791, SRR1407791, SRR1618514, SRR2060963, SRR2103855, 
103 SRR2103862, SRR554363, SRR1037365, SRR114084, SRR114085, SRR1460493,

104 SRR1951370, SRR2060964, SRR2103856, SRR2103863, SRR554364, SRR1037366,

105 SRR1184416, SRR1460494, SRR1951371, SRR2060965, SRR2103857, SRR2103864,

106 SRR554365, SRR1039534, SRR1407787, SRR1460495, SRR1951372, SRR2103851,

107 SRR2103858, SRR2103865, SRR556131, SRR1104083, SRR1104080, SRR1104086,

108 SRR1104087, SRR1407788, SRR1460504, SRR1951373, SRR2103852, SRR2103859 and

109 SRR2103866 (Li et al., 2012; Chen et al., 2013; Wei et al., 2014; Gao et al., 2015; Peng et al.,

110 2015); for E. sinensis: ERR336998, SRR1555734, SRR2170964, SRR579530, SRR1199039,

111 SRR1576649, SRR2170970, SRR579531, SRR1199053, SRR1735503, SRR2180019,

112 SRR579532, SRR1199058, SRR1735536, SRR2180020, SRR769751, SRR1199228,

113 SRR1735537, SRR546086, SRR770582, SRR1205971, SRR2073826 and SRR579529 (He et al.,

114 2012; Hui et al., 2014; Li et al., 2014; Sun et al., 2014; Liu et al., 2015; Xu et al., 2015; Cui et

115 al., 2015; Song et al., 2015; Wang et al., 2016); and for H. americanus: SRR2889572 and

116 SRR2891007 (Christie et al., 2015). From Euphausia crystallorophias I analyzed ERR264582

117 (Toullec et al., 2013) for the presence of a novel putative neuropeptide that was found in the

118 decapod transcriptomes.

119 The E. sinensis genome was downloaded from http://gigadb.org/dataset/100186, made into

120 a BLAST database and searched for neuropeptide genes as described previously (Veenstra, 121 2014).

122

123 Data analysis

124 The fasta files were extracted from the SRAs using the fastq command from the SRA

125 Toolkit from NCBI and then made into BLAST databases using BLAST+ (Camacho et al.,

126 2009). Using the P. clarkii predicted neuropeptide precursors, as well as a few other peptides, as

127 queries those databases were then searched using the tblastn command. A few neuropeptide

128 receptors were also analyzed. Identified reads that appeared to belong to the orthologous gene

129 were extracted from the database and then used to identify similar reads using the blastn

130 command. The latter were used as input for the Trinity program (Grabherr et al., 2011) and

131 resulting transcripts were recursively used as input until either the transcript stopped increasing

132 in length or it was judged to be complete based on the location of in-frame stop codons and/or a

133 signal peptide at the N-terminal of the protein predicted from the transcript. Calculations were 
134 run on a desktop computer with a AMD FX ${ }^{\mathrm{TM}}-6100$ six-core processor and $15.4 \mathrm{~Gb}$ of memory 135 under Ubuntu Linux.

136 This method is very efficient for the extraction of transcripts from single copy genes.

137 However, when there are several paralog genes that have not evolved a lot since their separation, 138 some paralogs may be missed, particularly when their expression levels are low. In those cases, a 139 selection of the particular neuropeptide precursors from which the non-conserved regions (such 140 as the signal peptides) had been removed was used as a query in a tblastn command and all the 141 obtained reads were then fed as input to the Trinity program. It can not be excluded that some 142 less well expressed paralogs of those genes that exist in multiple copies have been missed. This 143 may concern neuroparsin, $\mathrm{CHH}$ (crustacean hyperglycemic hormone), PDH (pigment dispersing 144 hormone) and possibly CFSH (crustacean female sex hormone).

145 Clustal Omega (Sievers et al., 2011) was used for sequence alignments and those were 146 inspected and, when needed, manually corrected using Seaview (Gouy, Guindon \& Gascuel, 147 2010), which was also used to extract the regions for making phylogenetic trees with FastTree 148 (Price, Dehal \& Arkin, 2010).

\section{Results}

Trinity is a fantastic tool to reconstruct large DNA sequences from very short reads.

152 However, not every sequence corresponds necessarily to a correct cDNA sequence or is

153 biologically interesting. One regularly finds more than one sequence derived from the same 154 gene. In the absence of a genomic sequence, as is the case here, it is not always possible to 155 determine which is the correct one. There are several common causes for the failure to produce a 156 single complete cDNA sequence. First, there may simply be insufficient reads available to 157 produce a complete contig. Secondly, there may be allelic variation that causes the elongation to 158 stop. Thirdly, alternative splicing, as is the case for genes encoding the agatoxin-like peptide, 159 Neuropeptide F 1, CNMamide, calcitonin and CHH, may have the same effect. Fourth, 160 recombining short sequences into a long one becomes very difficult in the case of repetitive 161 sequences. One or more reads containing a sequencing error can aggravate some of the other 162 problems, i.e. lack of sufficient reads, alternative splicing or allelic variants.

163 Most of the data analyzed here come from natural or almost natural populations that show 164 much larger genetic variation than that found in the typical laboratory animals like mice or rats. 
165 Furthermore, many neuropeptide genes code for a number of highly similar neuropeptide

166 paracopies and this makes it no doubt difficult to reconstruct the complete cDNA encoding such

167 precursors and when the various copies are only separated by convertase cleavage sites, the

168 problem may become acute. In one attempt to produce the E. sinensis FMRFamide precursor

169 mRNA Trinity produced a partial transcript that had a perfect internal repeat of 164 nucleotides

170 (Fig. S1), that must have been an artefact; a similar phenomenon is also present in the second

171 predicted orcokinin precursor from S. paramamosain (Bao et al., 2015; Fig. S1). Furthermore, I

172 have previously shown that some neuropeptide genes have alleles that differ in the number of

173 neuropeptide paracopies that they encode (Veenstra, 2010a; Veenstra, 2015). It is therefore not

174 surprising that a relatively large number of transcripts for neuropeptide precursors containing

175 multiple paracopies, such as FMRFamide, tachykinin, leucokinin, EFLamide etc, are incomplete

176 even though significant numbers of individual reads are found in the various SRAs. Predictions

177 by Trinity of neuropeptide precursors containing various paracopies may, for the same reasons,

178 contain errors. For example, the allatostatin A precursor from C. maenas does not code for some

179 of the previously identified peptides from this species (Duve et al., 1997), while the Trinity

180 transcripts of several other neuropeptide precursor sequences from the same species that have

181 been obtained by screening of classical cDNA libraries are identical (Klein et al., 1992, 1993;

182 Linck et al., 1993; Chung et al., 2006; Wilcockson and Webster 2008). Other transcripts that are

183 incomplete are often due to low expression levels.

184 While this work was in progress a draft genome for E. sinensis sinensis was published (Song 185 et al., 2016). This sequence was prepared using short sequence reads and therefore suffers from 186 the problems associated with this methodology (Richards and Murali, 2015). It is estimated that

187 about $67 \%$ of total sequence is present in the current draft. Several of the transcripts identified

188 here are not at all or only partially present in this genome and different exons of the same

189 transcripts are regularly found on different contigs. Its usefulness was, therefore, limited.

190 The decapod neuropeptide genes that were found are indicated in Fig. 1, where for

191 comparison the presence of neuropeptide genes of Daphnia pulex, a crustacean, and two insects,

192 the termite Zootermopsis nevadensis and the fruit fly Drosophila melanogaster, is also shown.

193 Note that although most neuropeptides have a single name, a few are known by different names,

194 e.g. the natalisins are sometimes called WXXXRamides and some researchers refer to the

195 peptides derived from the neuropeptide like precursor (NPLP) as HIGSLYRamides. Another 
196 example is the insect $\mathrm{CHH}$ homolog that was initially discovered by its effect on ion transport in

197 the hindgut and is therefore called ion transport peptide (ITP).

198 Many of the neuropeptide precursor transcripts seem complete, at least as far at the coding

199 region is concerned, while for others very significant parts were found. Since one of the

200 questions raised here is the presence of a particular neuropeptide gene, I have also added

201 neuropeptide genes for which individual reads from an SRA provide evidence for its existence in

202 the particular species, even though Trinity produced no contigs for transcripts from these genes.

203 All the sequences, both DNA and deduced amino acids, are listed in Tables S1-S8 in the

204 supplementary excel file.

205

206

Distribution.

207

Having all the SRAs it seemed interesting to look at where the various genes might be

208 expressed. Although it is possible to do this for all species involved, some are not very interesting as there is a very limited number of tissues sampled, while in other species the different tissues were sampled on different occasions and analyzed in different fashions, making

211 direct comparisons difficult. However, in the case of C. maenas a single publication reports

212 SRAs for a large variety of tissues (Verbruggen et al., 2015). Therefore, I used this species to

213 look at the expression of the various neuropeptide genes in different tissues. Those neuropeptide

214 receptors for which a contig of a significant size could be obtained and for which a likely ligand

215 could be deduced based on homology to a deorphanized protostomian GPCR (see Veenstra,

216 2016) were also included. Fhe actual number of individual reads is often small and quantification

217 of RNAseq reads is tricky due to the PCR amplification protocol used to create these libraries.

218 Furthermore, the actual number of samples remains very small, so care should be taken in the

219 interpretation of these data. Nevertheless, some interesting results are apparent (Table 1). Both

220 the neuroparsins and the CHHs are expressed in virtually every tissue. In the case of the

221 neuroparsin it is the neuroparsin 1 gene that is most abundantly expressed in all tissues, with the

222 other two neuroparsin transcripts present at much lower levels. However, the two identified $\mathrm{CHH}$

223 transcripts are differentially expressed, one hormone is most abundant in the central nervous

224 system and the eye (eyestalk), and the other in the intestine. Other neuropeptides found in the

225 intestine are tachykinin, allatostatin $\mathrm{C}$, the $\mathrm{B}$ transcript of the calcitonin gene, elevenin,

226 orcokinin, the agatoxin-like peptide and hyrg. The expression of CCHamide 2 and trissin in the 
227 hemolymph, presumably in hemocytes, is interesting to note as is the relatively large number of

228 neuropeptides found in the SRA derived from the epidermis.

229

230 Paralogs

231 There are several neuropeptide genes that have one or more paralog genes. These are

232 allatostatin $\mathrm{C}, \mathrm{CHH}$, moult inhibiting hormone (MIH), CCHamide, eclosion hormone,

233 neuroparsin, PDH, insulin and CFSH. In some cases these are sufficiently different within the

234 same species and sufficient similar between different species, that they clearly derive from

235 different genes. This is the case for allatostatin C, CCHamide, insulin, neuropeptide F and

236 eclosion hormone.

237 In the case of PDH, it is a bit more complicated. Variable numbers of PDH precursors were

238 found in the seven decapod species. One group of precursors encoding PDH-like peptides

239 distinguishes itself by an insertion of two amino acid residues in the predicted mature PDH. Such

240 a predicted peptide was first found in P. clarkii (Veenstra, 2015), but since it was based on a

241 single read in one species, it seemed premature to give it a distinct name. Now that complete

242 precursor sequences are available and this peptide appears to be ubiquitously present in

243 decapods, I propose to call it elongated PDH, or ePDH, to distinguish it from the more classical

244 forms of these peptides (Fig. 2). The ePDH gene is one of the few genes that is present on a

245 single contig of the draft genome from $E$. sinensis. It consists of three exons of which the first

246 one is non-coding (Fig. 3). Partial sequence for one of the classical PDH genes show the intron

247 between the two coding exons to be conserved.

248 In the case of neuroparsin, PDH, CHHs and its homolog MIH it is not always as clear that

249 they represent different genes with unambiguous orthologs in different species. In some cases the

250 observed differences could reflect allelic variations of a single gene or recent local gene

251 duplications. Although no decapod genomes have been completely sequenced and the $E$. sinensis

$252 \mathrm{CHH}$ genes are mostly very fragmentary, such local gene duplications are well known for $\mathrm{CHH}$

253 in decapods (Gu \& Chan, 1998; Gu, Yu \& Chan, 2000; Dircksen et al., 2001; Webster, Keller \&

254 Dircksen, 2012) as well as Chelicerates (Veenstra, 2016) and particularly in decapods the

255 number of CHH genes can be quite large (Webster, Keller \& Dircksen, 2012).

256

257

$\mathrm{CHH} / \mathrm{MIH}$ 
The $\mathrm{CHH} / \mathrm{MIH}$ neuropeptide family is characterized by $\mathrm{CHH}, \mathrm{MIH}$, mandibular organ-

259

260

261

262

263

264

265

266

267

268

269

270

271

272

273

274

275

276

277

278

279

280

281

282

283

284

285

286

287

288 inhibiting hormone (MOIH), vitellogenesis-inhibiting hormone (VIH) and gonad-inhibiting hormone (GIH). These hormones have been identifed by different physiological assays, but are in many cases pleiotropic. For example, although identified in different biological assays VIH and GIH are the same hormone. These peptides can be subdivided in two subfamilies, the CHHs proper and the other peptides. The precursors from the two groups differ in that the CHHs are produced together with a $\mathrm{CHH}$-precursor related peptide, while the prepropeptides from the other homornes consist exclusively of a signal peptide and the sequence of the mature hormone (Webster, Keller \& Dircksen 2012). Three of the CHH/MIH transcripts identified here defy those rules as they do not have the $\mathrm{CHH}$-precursor related peptide, yet on phylogenetic trees they form a separate branch that is closer to the $\mathrm{CHH}$ than to the MIH cluster (Fig. 4). Adding more sequences to the tree does not change this (data not shown). In the E. sinensis draft genome many sequences corresponding to these hormones are located on small scaffolds making it impossible to ascertain whether or not these genes are clustered.

\section{CFSH}

The CFSH is a recent discovery (Zmora \& Chung, 2014) and consequently we still know very little of this very interesting hormone. In P. clarkii three related proteins were previously identified (Veenstra, 2015). In five of the other six decapod species two to four such hormones were found, but not in $H$. americanus, where there are no ovary transcriptomes. The primary sequence of these different putative hormones is not very well conserved, but the cysteine residues are (Fig. 5). The phylogenetic tree of these hormones suggests an initial gene duplication giving rise to two types of CFSH, that I have arbitrarily called CFSH 1 and 2 (Fig. 6). In most species both CFSH 1 and 2 were found, but in in L. vannamei only three CFSH 1 paralogs were found and no CFSH 2. In the draft genome of E. sinensis CFSH 1 and $2 \mathrm{~b}$ genes contain a single coding exon. The CFSH gene $2 \mathrm{a}$ transcript is incomplete and it is not clear from the genomic sequence what it is. This hormone was initially isolated from the eyestalk of the crab Callinectes (Zmora \& Chung, 2014), while it in the crayfish P. clarkii it seemed to be strongly expressed in the ovary. It seemed therefore of interest to see whether these hormones might be expressed in the ovary in other decapods also. No significant expression was found in the ovaries of $M$. rosenbergii and L. vannamei [ 1 to 2 reads maximum for each hormone in an 
289 SRA], but 9 reads corresponding to L. vannamei CFSH 1c (as well as 1 each for 1a and $1 \mathrm{~b}$ ) are

290 present in SRR2060962 from the L. vannamei testis. In E. sinensis expression is similar to that in

291 C. maenas (Table 1), high expression levels in the eyestalk and a few reads only in the ovary.

292 For S. paramamosain and H. americanus there are insufficient data to answer this question.

293

294 Neuroparsins and receptors

295 Three to four neuroparsin transcripts were identified in each of the seven decapod species.

296 Three of the E. sinensis genes were found in the draft genome, two of these (neuroparsins 3 and

297 4) are on the same scaffold in a tail to tail configuration, where the start and stop codons of the

298 two genes are separated by 11960 and 9045 nucleotides respectively (Fig. 7). These are the two

299 E. sinensis genes that are most similar to one another, suggesting that they may reflect the most

300 recent neuroparsin gene duplication in this species. As both these genes seem to have direct

301 orthologs in S. paramamosain and C. maenas, that particular gene duplication possibly occurred

302 in a common ancestor of the three crab species (Fig. 8). The neuroparsin receptor was recently

303 identified as a venus kinase receptor (Vogel et al., 2015); two such receptors are found in all

304 seven decapod species (Table S8). The phylogenetic tree made of the various venus kinase

305 receptors suggests that the other arthropods venus kinase receptors are equally similar to both

306 decapod receptors (Fig. 9).

307

308 Insulin-like peptides and receptors

309 Three different insulin-related peptides were identified. These are the well known

310 androgenic insulin-related peptide (Fig. 10), an insulin-like peptide (Fig. 11) that seems most

311 similar to the Drosophila insulin-like peptides 1-6 (Nässel \& vanden Broeck, 2015), and a

312 peptide that is orthologous to Drosophila insulin-like peptide 7 and that has been called relaxin

313 (Fig. 12). The latter was previously identified in Sagmariasius and P. clarkii (Chandler et al.,

314 2014; Veenstra, 2015). As can be seen from the figures, the androgenic insulin-like peptide is the

315 least conserved of those three (Figs. 10-12). Insulin-related peptides use two different types of

316 receptors, the typical tyrosine kinase receptor and GPCRs. Insects typical have one gene coding

317 an insulin tyrosine kinase receptor and have one or two GPCRs that are related to the vertebrate

318 relaxin receptors RXFP1 and RXFP2. Given the interest in the androgenic insulin-like peptide

319 both for its intriguing physiology as a peptidergic sex hormone and for its commercial potential 
320 (Ventura \& Sagi, 2012), I also analyzed the likely insulin receptors.

321 The typical insulin tyrosine kinase receptor, similar to the one recently described from $M$. 322 rosenbergii (Sharabi et al., 2016), was also found in the other six decapods (Table S8). Two

323 receptors similar to the vertebrate relaxin receptors RXFP1 and RXPF2 were identified. Those

324 two GPCRs are most similar to the Drosophila receptors CG31096 and CG34411, also known as

325 leucine-rich repeat containing GPCR- 3 and 4 (LGR3 and LGR4) respectively. However, the

326 much weaker expression of those receptors made it impossible to deduce their complete cDNA

327 sequences and in some cases no contigs could be obtained. Interestingly the SRA from the $E$.

328 sinensis accesory gland (SRR2170964) not only shows very large number of reads for the

329 androgenic Insulin-like peptide, but also very significant expression of the insulin tyrosine kinase

330 receptor and a somewhat lower expression of the ortholog of Drosophila LGR3.

331

332 Splice variants

333 There were a number of neuropeptide encoding cDNAs that revealed splice variants. Those

334 that concerned the untranslated regions were ignored, but there are five neuropeptide genes that

335 have alternative transcripts producing different precursors: the CHHs, CNMamide, neuropeptide

336 F 1, calcitonin and the agatoxin-like peptide. In the case of neuropeptide F 1, there is an extra

337 exon sliced into the sequence of the peptide, as described previously from insects and D. pulex

338 (Roller et al., 2008; Nuss et al., 2010; Dircksen et al., 2011). The CNMamide gene in the termite

339 Zootermopsis contains five coding exons, the last two of which are alternatively added to the first

340 three and then produces a different CNMamide-like peptide. In four of the seven decapods

341 similar alternative splice products were found for the CNMamide precursor. However, while the

342 mature peptide derived from the major splice form is well conserved, the second is much less so

343 (Fig. 13). Two to four splice variants (Fig. S2) were found for the recently discovered $\mu$ -

344 agatoxin-like peptide (Sturm et al., 2015). As in some insects (Veenstra, 2014), the calcitonin

345 gene produces two different transcripts, encoding different types of calcitonin, that are similar to

346 the insect calcitonins (Fig. S3). In L. vannamei, M. rosenbergii, H. americanus and P. clarkii the

347 second transcripts are predicted to produce a calcitonin-like peptide that does not have one but

348 two cysteine bridges at is N-terminus (Fig. 14). The calcitonin gene is absent from the E. sinensis

349 draft genome, and hence it is impossible to compare the insect and decapod calcitonin gene

350 structures. 
352 Other peptides.

353 In several cases novel neuropeptides have been detected by mass spectrometry. These are 354 often structural variants of well known neuropeptides such as the RFamides, tachykinins and 355 allatostatins A or B (e.g. Ma et al., 2008, 2009, 2010). However, not all peptide sequences 356 identified this way belong to known neuropeptides. From H. americanus, C. maenas and $L$.

357 vannamei other peptide sequences have been reported. The ones from C. maenas have previously 358 been suggested to represent fragments of cryptocyanin (Ma et al., 2009), and this was confirmed 359 (Fig. S4). Several of the peptides from H. americanus are shown here to represent fragments of 360 thymosin, actin or histone $2 \mathrm{~A}$, however the origins of others remain unclear (Fig. S4). The one 361 peptide reported from L. vannamei, L/IPEPEDPMAEAGHEL/I (Ma et al., 2010), is more 362 interesting, as it could potentially be part of a novel neuropeptide (precursor). This sequence is 363 part of a small protein that has a signal peptide followed by a peptide containing a small piece that is very well conserved (Fig. 15). However, it lacks the classical convertase cleavage sites that one usually finds in neuropeptide precursors and hence its status as a neuropeptide is unclear. Such proteins are also found in the other decapods. Although it was not possible for Trinity to produce a complete contig for S. paramamosain, a similar sequence is present in the databanks for Scylla olivacea. I was unable to find similar proteins in insects, but an orthologous protein was detected in the SRA from Euphausia crystallorophias. The latter sequence shows that the only conserved part is the same as in the decapods (Fig. 15). This peptide was called hyrg (pronounced hirg), for four of the conserved amino acids. Interestingly, the eyestalk seems to be the tissue where expression of hyrg is the highest (Table 1), thus suggesting that it is likely a neurohormone.

\section{Discussion}

376 Insects and decapods are estimated to have had their last common ancestor about 596 Mya, while similar estimates for the common ancestor of crabs and lobsters on the one hand and that

378 for termites and flies on the other are 322 and 348 Mya respectively (Hedges et al., 2015). The gross morphology of decapods has changed a lot less than that of insects and when one compares the respective neuropeptidomes of those two groups, it is clear that those are similarly much better conserved in decapods than in insects (Fig. 1). Most of the changes in insects are losses of 
382 neuropeptides that are particularly pronounced in flies, and perhaps even more so in $D$.

383 melanogaster.

384 Whenever in this study a particular gene has not been identified from a decapod species, 385 either one of the following is true: (1), the gene is not expressed at high levels and there are 386 relatively small amounts of RNAseq reads, (2) the gene is expressed predominantly in tissues 387 that have not been sampled in the species in question or (3) the gene has several paralog genes

388 (PDH, CHH, neuroparsin) and it may not have the same number of paralogs in all species and/or 389 some of those paralogs may be expressed in tissues that were not sampled. A combination of (1) 390 and (2) likely explains the absence of some of the neuropeptide genes in S.paramamosain. From

391 that species the eyestalk was not analyzed, even though this tissue is by far the richest source of

392 neuropeptides. Nevertheless, the existence of several $S$. paramamosain neuropeptide genes could

393 be inferred from individual RNAseq reads, while the few genes that are completely lacking are

394 only weakly expressed in the other species. The androgenic peptide was found neither in $C$.

395 maenas nor H. americanus. As in H. americanus only the nervous system was included in the 396 analysis, this is to be expected. In the case of C. maenas, it is plausible that the testis samples did 397 not include the accessory gland, or that the sample was taken at a moment in the life cycle of the 398 animal that expression of this peptide is low or non-existent. With one exception, in all other instances where a transcript seems to be lacking it is either from a gene for which an alternative transcript was found (e.g. in the case of the CNMamide and Neuropeptide F 1 genes), or the

401

402

403

404

405

406

407

408

409

410

411

412

number of paralogs may differ between the various species (neuroparsin, CHH, MIH, PDH). The only exception is a typical MIH in H. americanus. In spite of using the MIH sequence of the closely related species $H$. gammarus (Ollivaux, 2006) as a query in the BLAST program, no transcript was found in the H. americanus SRAs. Although MIH has been reported by mass spectrometry from the stomatogastric ganglion of H. americanus (Ma et al., 2008), this peptide is not a typical MIH but has the structure of a CHH (Chang, Prestwich \& Bruce, 1990). This suggests that in H. americanus the MIH function is assured by a member of the first rather than the second subfamily of these hormones. It also suggests that in this species the second subfamily was lost.

\section{Neuropeptide evolution}

It thus appears that the neuropeptidome of decapods has been remarkably well conserved 
413 during evolution. Differences that are found between the insect and decapod neuropeptidomes

414 are the loss or the gain of a neuropeptide. Although there possibly still remain arthropod

415 neuropeptides to be discovered, it appears that the loss of neuropeptides in decapods is limited to

416 a single neuropeptide, i.e. allatotropin. Allatotropin is present in mollusks, annelids as well as

417 chelicerates (Veenstra 2010a, 2011, 2016) and hence, it must have been present in the arthropod

418 ancestor. Small peptides are sometimes hard to find using the BLAST program and allatotropin

419 is no exception to this rule (Veenstra, Rodriguez \& Weaver, 2012). Nevertheless, as I was

420 neither able to find even a single read correponding to its receptor, including in the very

421 abundant number of transcriptome reads from $H$. americanus, I conclude that this peptide was

422 most likely lost. In the termite and the fruit fly on the other hand, more neuropeptides are

423 missing, particularly in Drosophila. At first sight insects, as a group, lack EFLamide, the

424 androgenic insulin-like hormone, $\mathrm{CFSH}$ and ePDH. However, the recent identification of an

425 EFLamide receptor in Platynereis dumerlii as a TRH GPCR ortholog (Bauknecht \& Jékely,

426 2015) and the presence of such a GPCR in Nilaparvata lugens (Tanaka et al., 2014) suggests that

427 some insects may have such a gene. As described below, it is plausible that the androgenic

428 peptide has an insect ortholog. What seems really different is that many insect species, in

429 particular holometabolous species, have lost several neuropeptides (Derst et al., 2016). Thus

430 Drosophila no longer has genes for elevenin, vasopressin, allatotropin, allatostatin CCC,

431 EFLamide, neuroparsin, calcitonin, ACP, eclosion hormone 2, neuropeptide F 2 and it also lost

432 the possibility to produce alternative transcripts from the CNMamide and neuropeptide F1 genes.

433 The beetle Tribolium castaneum on the other hand still has most of those neuropeptides, but lost

434 allatostatin A, corazonin and leucokinin.

435

436 New neuropeptides

437 Since the last common ancestor of decapods and insects - estimated to have lived 596 Mya

438 (Hedges et al., 2015) - very few neuropeptides seem to have been added to either of the two

439 lineages. Novel neuropeptide genes that have appeared seem all to have originated by duplication

440 from existing ones and are easily recognized as the paralogs of the parent genes. Examples of

441 such genes are the various paralogs of $\mathrm{CHH}$ and $\mathrm{MIH}, \mathrm{PDH}$ and neuroparsin in crustaceans and

442 in insects the typtopyrokinin and SIFamide paralogs as well as the great variety of adipokinetic

443 hormones (all orthologs of crustacean RPCH). The only exception may be hyrg, the precursor for 
444 the peptide initially identified from L. vannamei (Ma et al., 2010). This peptide, that is well

445 expressed in the eyestalk and the midgut, has a distribution typical of a neuroendocrine peptide.

446 As I was unable to find it outside of crustaceans, it could be a novel invention of this group. The

447 structure of this putative neuropeptide precursor is somewhat reminiscent of limostatin, a small

448 neuroendocrine protein discovered in Drosophila that intereacts with a GPCR (Alfa et al., 2015)

449 previously identified as the receptor for neuropeptide pyrokinin 1 (Cazzamali et al., 2005). The

450 similarity between limostatin and hyrg resides in the apparent absence of conventional

451 convertase sites in these putative neuropeptide precursors [those postulated to function in the

452 limostatin precursor (Alfa et al., 2015) seem highly unusual (Veenstra, 2000)]. In the same

453 context the Drosophila sex peptide comes to mind, as it also acts on a neuropeptide receptor

454 without having neither a well conserved structure nor the typical neuropeptide convertase

455 cleavage sites (Kim et al., 2010). Perhaps one or more of these proteins represent newly evolved

456 ligands for existing neuropeptide receptors that could potentially become novel neuropeptides.

457

458

Missing neuropeptides

459 Many decapod neuropeptides have been identified by mass spectrometry over the years (e.g.

460 Stemmler et al., 2007a,b; 2010; Christie et al., 2008; Ma et al., 2008, 2009, 2010; Dickinson et

461 al., 2008, 2009a,b). Most of those were identified in the various SRAs, although not always in

462 exactly the same molecular form. In particular, I was unable to find some of the analogs of

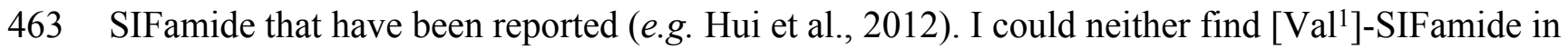

464 any species, however this peptide seems to be present in the stomatogastric nervous system

465 (Christie et al., 2006) and this might explain its absence from the various SRAs. Several of the

466 peptides previously described from these data that did not appear to be neuropeptides could be

467 identified as being part of well known proteins and it also allowed me to identify the hyrg

468 trancript. However, there are three neuropeptides that either have been reported or suggested to

469 be present in decapods that were not found in any of the SRAs from the seven decapod species

470 studied here. These are a pituitary adenylate cyclase activating polypeptide (PACAP) from $L$.

471 vannamei (Lugo et al., 2013), a GnRH-like peptide from P. clarkii (Guan et al., 2014) and two

472 kisspeptins from $M$. rosenbergii (Thongbuakaew et al., 2016). None of these peptides could be

473 found in any of the SRAs, neither those from the species from which they were reported, nor

474 from any of the other species. In two cases (PACAP and GnRH), the amino acid sequences of 
475 the peptides have been published from the same species used here, so my inability to find these 476 peptides is not due to significant sequence differences between the species used for bioinformatic 477 analysis and those from which the peptides were identified. I was neither able to find evidence 478 for the receptors for such peptides in any of decapods. The GnRH receptor identified from the 479 ovary of the oriental river prawn Macrobrachium nipponense is the corazonin receptor ortholog 480 (Du, Ma \& Qiu, 2015), implying that corazonin is its ligand. Given the strong conservation of the 481 decapod neuropeptidome described here, I conclude that is highly unlikely that any of those three 482 peptides is present in decapods.

483

484 Functional aspects

485 Conservation of structure does not necessarily imply conservation of function. The function 486 of crustacean RPCH and its insect ortholog AKH are distinctly different. A neuropeptide 487 sequence does not reveal its function, but the distribution of its receptor may give some clues. 488 FMRFamide is known to effect muscle contraction in decapods (Worden, Kravitz \& Goy, 1995), 489 the expression of its putative receptor in muscle, heart and the epidermis (that contains muscle as well) suggests that it has similar effects. The simultaneous expression of elevenin and a putative elevenin receptor in the midgut suggests that is has a digestive function. The hormone

492 GPA2/GPB5 was suggested to be an antidiuretic hormone in Drosophila (Sellami, Agricola \& 493 Veenstra, 2011) and was subsequently shown to stimulate sodium reabsorption in the mosquito

494 hindgut (Paluzzi, Vanderveken \& O'Donnell, 2014). The very abundant expression of its receptor 495 in the gill suggests that its function C. maenas may well be similar. An interesting difference 496 between insects and decapods is the presence of ecydysis triggering hormone in the decapod 497 nervous system and eye(stalk); in insects this peptide seems to be exclusively present in cells 498 associated with the tracheal system and absent from the central nervous system (Roller et al., 499 2010). It will be interesting to know whether the function of ecdysis triggering hormone within 500 the decapod nervous system is related to ecdysis behavior.

502 Intestine

503 Neuropeptides in the intestine are typically produced by enteroendocrine cells. CHH (Chung, 504 Dircksen \& Webster, 1999), SIFamide and tachykinin immunoreactive enteroendocrine cells 505 (Christie et al., 2007) have been previously described from decapods. No SIFamide reads were 
506 found in the C. maenas intestine SRA, but allatostatin C, calcitonin-B, elevenin, orcokinin and

507 hyrg were all present in seemingly significant numbers of reads (Table 1). This ensemble of gut

508 neuropeptides differs significantly from what is known from the Drosophila midgut (Veenstra \&

509 Ida, 2014), even though tachykinin, allatostatin C and orcokinins are present in both, while the

510 calcitonin B transcript is abundant in phasmid midgut SRAs (Veenstra, 2014).

511

$512 \mathrm{CHH}$ and $\mathrm{MIH}$

513 The neuropeptides related to $\mathrm{CHH}$ are amongst the best known crustacean hormones

514 (excellent review by Webster, Keller \& Dircksen, 2012). As was expected based on the

515 literature, several molecular forms were found. There are reasons to think there may be more of

516 these hormones than reported here. First of all, the few decapod $\mathrm{CHH}$ genes that have been

517 identified are typically present in clusters and in Metapaeneus ensis 16 such genes have been

518 found (Gu \& Chan, 1998). Secondly, as shown here and elsewhere (e.g. Hsu et al., 2006; Li et

519 al., 2010; Ventura-López et al., 2016) some of these genes are differentially expressed. Thus, if a

520 gene is predominantly expressed in a tissue not included in the analysis, it may not be found.

521 Finally, since these hormones are similar in structure, it is possible that Trinity would have

522 problems producing all contigs.

523 The biological activities of these hormones vary widely and the hormones with very similar

524 sequences may have quite different physiological effects (e.g. Webster, Keller \& Dircksen, 2012;

525 Luo et al., 2015). It is for this reason impossible to interpret the meaning of the three predicted

526 hormones that defy classification as either a CHH-like or MIH-like hormone (Figs. 5).

527

$528 \mathrm{PDH}$

529 There are generally within the same species several precursors coding the shorter, more

530 classical, PDHs, those different precursors code sometimes for the same mature peptide. It seems

531 plausible that some of these differences reflect either allelic variations of a single gene or recent

532 local gene duplications. Most of the species have two or more different predicted mature PDH

533 peptides. It has previously been shown that the two PDHs from the crab Cancer productus have

534 different functions, one is released as a hormone into the hemolymph, while the other is used

535 within the central nervous system (Hsu et al., 2010). As the tissue used for the S. paramamosain

536 transcriptome did not include the eyestalk it is thus not surprising that the hormonal PDH is 
537 lacking from the deduced transcriptome in this species. ePDH is not expressed in the eyestalk

538 and one might therefore be tempted to think it is not released into the hemolymph. However it is

539 present in the L. vannamei transcriptome that was produced from abdominal muscle,

540 hepatopancreas, gills and pleopods (Ghaffari et al., 2014) and thus is likely produced somewhere

541 in the periphery (this transcriptome contains relatively few neuropeptides as it includes neither

542 the central nervous system nor the intestine).

543

544 CFSH

545 CFSH was discovered very recently in the crab Callinectes sapidus (Zmora \& Chung, 2014)

546 and consequently we know still very little of this extraordinarily interesting hormone. I

547 previously reported the presence of both CFSH and two homologous proteins in P. clarkii

548 (Veenstra, 2015). Now that there are a few more sequences available, it appears that this gene

549 commonly has several paralogs. Some of these seem to have a relatively recent origin, as the

550 most closely related sequence comes from the same species (Fig. 6). The independent gene

551 duplications of these proteins as well the great sequence variability between and within species

552 may indicate that all these hormones act on the same receptor. Given the relatively large size of

553 these hormones one might expect a leucine rich repeat G-protein coupled receptor or a dimeric

554 protein kinase, perhaps one of the two venus kinase receptors, but this remains speculation. The

555 primary structure of CFSH is not very well conserved and its receptor is unknown. Hence, we

556 don't know whether an orthologous hormonal regulatory system might be present in other

557 arthropods, like e.g. insects (given the great similarity in their neuropeptidomes this seems a

558 distinct possibility, at least in the more primitive insects). It seems that the expression of this

559 hormone in the ovary of $P$. clarkii (Veenstra, 2015) is unusual, as it was not found in any of the

560 other decapods for which an ovary SRA is available.

561

562 Insulin and neuroparsin

563 Other intriguing neuropeptides are the neuroparsins and the insulin-related hormones. There

564 are three different insulin-like hormones. There are also three different insulin receptors, the

565 classical tyrosine kinase and two G-protein coupled receptors. What I have called insulin is the

566 hormone most similar to the Drosophila insulin-like peptides 1-6, which function as growth

567 hormones and are also important for reproduction and that signal through the classical tyrosine 
568 kinase receptor (Nässel \& vanden Broeck, 2015). The same receptor is also present in decapods

569 as shown here and elsewhere (Veenstra, 2015); it has recently been characterized in two

570 decapods (Aizen et al., 2016; Sharabi et al., 2016). Both insulin and neuroparsins activate

571 tyrosine kinase receptors. However, whereas the actions of insulin in insects are relatively well

572 understood due to very extensive research on these peptides in Drosophila (Nässel \& vanden

573 Broeck, 2016), the function of neuroparsin is less clear, as it is absent from Drosophila

574 melanogaster (Veenstra, 2010b). It is interesting to note that some species have several insulin

575 genes and few if any neuroparsin genes (Drosophila, Acyrthosiphon, Zootermopsis), while

576 decapods and Locusta have several neuroparsin transcripts and only a single insulin gene,

577 suggesting some complementation between these two hormones. Indeed, in some cases, such as

578 vitellogenesis in the mosquito both hormones have synergistic effects (Brown et al., 1998; Dhara

579 et al., 2013), however in the migratory locust they act antagonistically (Badisco et al., 2011).

580 Initially isolated from the migratory locust L. migratoria (Girardie et al., 1989) neuroparsin was

581 shown to have strong anti-juvenile hormone effects, effecting both reproduction and

582 metamorphosis (Girardie et al., 1987). It has been shown that neuroparsin RNAi also inhibits

583 vitellogenesis, and hence reproduction, in the decapod Metapenaeus ensis (Yang et al., 2014).

584 The receptor for this hormone was recently identified in mosquitoes as a venus kinase receptor

585 (Vogel et al., 2015), a type of receptor that was lost in chordates during evolution (Dissous,

586 2015). Although orthologous venus kinase receptors are present in other arthropod genomes

587 (notably Limulus, Strigamia and Stegodyphus, Table S8) as well as mollusks (Vanderstraete et

588 al., 2013), no neuroparsin orthologs could be found in those species. The evolutionary origin of

589 neuroparsin is therefore unclear and it is not known whether species that seem to lack

590 neuroparsin need a hormone ligand to activate the venus kinase receptor (Dissous, 2015). The

591 presence of two such receptors in decapods is intriguing, but has also been found in Lepidoptera

592 and trematodes (Dissous, 2015).

593

594 The other insulin-like peptides

595 Insects and decapods share many neuropeptides and it is not surprising that the various

596 decapod insulin-related hormones also have insect orthologs. The insulin-like hormone I have

597 called relaxin is an ortholog of Drosophila insulin-like peptide 7. This hormone is not only

598 present in insects, but also in ticks, spider mites, mollusks and even acorn worms (Veenstra, 
599 2010a; Veenstra, Rombouts \& Grbić , 2012). As previously pointed out, this hormone is only

600 present in the genomes of those species that also have an ortholog of Drosophila gene CG34411, 601 encoding LGR4 that is homologous to vertebrate relaxin GPCRs (Veenstra, Rombouts \& Grbić , 6022012 ; Veenstra, 2014). This suggests that this GPCR functions as a receptor for the arthropod 603 relaxins. It must be noted that this does not exclude the possibility that arthropod relaxins may 604 also signal through the classical insulin tyrosine kinase receptor. In fact, there is evidence from 605 Drosophila that this is so (Linneweber et al., 2014).

606 Drosophila has an eighth insulin-like hormone that was initially discovered because it is 607 secreted by the imaginal discs (Colombani et al., 2015; Garelli et al., 2015). However, data from 608 fly atlas (Chintapalli, Wang \& Dow, 2007) show that it is also expressed by the ovary. This 609 hormone was suggested to be acting through the GPCR encoded by Drosophila gene CG31096 610 encoding LGR3 (Veenstra, 2014) and this has now been confirmed (Vallejo et al., 2015; Garelli 611 et al., 2015). LGR3 is also related to vertebrate GPCRs binding relaxin. As reported previously it 612 has a P. clarkii ortholog (Veenstra, 2016), and as shown here is generally present in decapods.

613 Combined these data suggest that LGR3 is the receptor for the androgenic insulin-like peptide

614 from the accessory gland. The absence of clear sequence homology between the Drosophila and

615 decapod peptides is not surprising, as the primary sequence of this hormone is poorly conserved 616 in both decapods (Fig. 10) and insects [other insects almost certainly have such a peptide, since

617 they have the receptor, but only within flies is it possible to find orthologs using the BLAST

618 program]. Interestingly, both these hormones are produced by gonads or associated accessory 619 glands. At first sight it seems that in crustaceans it is predominantly the male that produces it, 620 while in adult flies it is the female. However, work on the expression of LGR3 in Drosophila 621 shows it to be important for the development of both male and female specific sexual characters 622 (Meissner et al., 2016) and it is perhaps better considered a (sexual ?) maturation hormone for 623 both sexes. This would also make it easier to understand how during evolution it was coopted by 624 the imaginal discs. In decapods the male has two $\mathrm{Z}$ chromosomes and is the default sex (Parnes 625 et al., 2003; Staelens et al., 2008; Ventura et al., 2011; Cui et al., 2015). Therefore, one would 626 expect females to have a mechanism (not necessarily hormonal) to escape becoming a male and 627 might thus expect a gynogenic rather than an androgenic hormone (this is one of the reasons why 628 CFSH is so interesting). Even in decapods there is now evidence that the androgenic insulin-like 629 peptide is not specific for males. Thus, in S. paramamosain it is also expressed by the ovary and 
630 at higher levels at the end of vitellogenesis (Huang et al, 2014). While the relative levels of 631 expression may seem low as compared to those of actin (Huang et al, 2014), the actual quantities 632 of peptide produced may well rival those made by the accessory gland, considering that the 633 ovary is so much larger [could the accessory gland be the remnants of an embryonic ovary 634 anlage ?]. Given the effectiveness of RNAi in crustaceans and the strong phenotypes obtained in 635 the absence of androgenic peptide (Ventura et al., 2009), the hypothesis that LGR3 is important 636 in the transduction of the androgenic peptide signal can be tested. As with relaxin, a GPCR 637 specifically activated by the androgenic insulin-like peptide does not exclude the possibility that 638 it may also act on the classical insulin tyrosine kinase receptor, as shown by recent experiments 639 in the decapod Sagmariasus (Aizen et al., 2016). Possible relations between the decapod insulin640 related peptides and their receptors are illustrated in Figure 16.

641 It is of interest to note that the mammalian GPCR most similar to LGR3 is RXFP2, the 642 receptor for insulin-related peptide 3. The latter hormone was initially discovered from the testis 643 and is important not only to insure testicular descent (Adhama, Emmen \& Engel, 2000) but also 644 in the female reproductive system (Satchell et al., 2013). Thus the data suggest that not only the 645 structures of the receptor and its ligand are recognizably similar, but so might be their function.

646 This is rather interesting, as most neuropeptides with orthologs in both proto- and deuterostomia 647 have quite different functions in these two groups.

\section{Conclusions}

650 Decapod neuropeptidomes are highly conserved and share many neuropeptides with insects. 651 Although a shared neuropeptide structure does not necessarily translate into a shared function, it 652 should allow for the rapid identification receptors in decapods in those cases where the 653 orthologous insect receptor is known.

\section{Acknowledgements}

656 I thank Drs. Simon Webster and Haihui Ye for their constructive criticism that helped improve 657 the manuscript. I am also grateful to all those who collected the original data I used, as well as to 658 those who wrote the programs employed for their analysis.

659

660

\section{References}

661 
662 Adhama IM, Emmen JMA, Engel W. 2000. The role of the testicular factor INSL3 in

663 establishing the gonadal position. Molecular and Cellular Endocrinology 160:11-16.

664 doi:10.1016/S0303-7207(99)00188-4.

665

666 Aizen J, Chandler JC, Fitzgibbon QP, Sagi A, Battaglene SC, Elizur A, Ventura T. 2016.

667 Production of recombinant insulin-like androgenic gland hormones from three decapod species:

668 in vitro testicular phosphorylation and activation of a newly identified tyrosine kinase receptor

669 from the Eastern spiny lobster, Sagmariasus verreauxi. General and Comparative Endocrinology

670 229:8-18. doi: 10.1016/j.ygcen.2016.02.013.

671

672

673

Alfa RW, Park S, Skelly KR, Poffenberger G, Jain N, Gu X, Kockel L, Wang J, Liu Y, Powers

674

675

676

677 AC, Kim SK. 2015. Suppression of insulin production and secretion by a decretin hormone. Cell Metabolism 21:323-33. doi: 10.1016/j.cmet.2015.01.006.

Badisco L, Marchal E, Van Wielendaele P, Verlinden H, Vleugels R, Vanden Broeck J 2011. RNA interference of insulin-related peptide and neuroparsins affects vitellogenesis in the desert

678

679

680

681

682

683

684

685

686

687

688

689 locust Schistocerca gregaria. Peptides 32:573-580. doi:10.1016/j.peptides.2010.11.008.

Bao C, Yang Y, Huang H, Ye H. 2015. Neuropeptides in the cerebral ganglia of the mud crab, Scylla paramamosain: transcriptomic analysis and expression profiles during vitellogenesis. Scientific Reports 5:17055. doi: 10.1038/srep17055.

Bauknecht P, Jékely G. 2015. Large-Scale Combinatorial Deorphanization of Platynereis Neuropeptide GPCRs. Cell Reports 12:684-693. doi: 10.1016/j.celrep.2015.06.052.

Brown MR, Graf R, Swiderek KM, Fendley D, Stracker TH, Champagne DE, Lea AO. 1998. Identification of a steroidogenic neurohormone in female mosquitoes. Journal of Biological Chemistry 273:3967-3971. doi: 10.1074/jbc.273.7.3967.

690

Bungart D, Hilbich C, Dircksen H, Keller R. 1995. Occurrence of analogues of the myotropic BLAST+: architecture and applications. BMC Bioinformatics 10:421. doi: 10.1186/1471-2105-

697 10-421.

698

Cazzamali G, Torp M, Hauser F, Williamson M, Grimmelikhuijzen CJP. 2005. The Drosophila gene CG9918 codes for a pyrokinin-1 receptor. Biochemical and Biophysical Research Commununications 335:14-9. doi:10.1016/j.bbrc.2005.07.038.

704 of a novel insulin-like peptide and insulin binding proteins in the Eastern rock lobster 
708 Chang ES, Prestwich GD, Bruce MJ, 1990. Amino acid sequence of a peptide with both molt709 inhibiting and hyperglycemic activities in the lobster, Homarus americanus. Biochemical and

710 Biophysical Research Commununications 171:818-826. doi:10.1016/0006-291X(90)91219-I.

711

712

713

714

715

716

717

718

719

720

721

722

723

724

725

726

727

728

729

730

731

732

733

734

735

736

737

738

739

740

Chen X, Zeng D, Chen X, Xie D, Zhao Y, Yang C, Li Y, Ma N, Li M, Yang Q, Liao Z, Wang H. 2013. Transcriptome analysis of Litopenaeus vannamei in response to white spot syndrome virus infection. PLoS One 8:e73218. doi: 10.1371/journal.pone.0073218

Chintapalli VR, Wang J, Dow JAT. 2007. Using FlyAtlas to identify better Drosophila melanogaster models of human disease. Nature Genetics 39:715-720. doi:10.1038/ng2049.

Christie AE. 2014. Expansion of the Litopenaeus vannamei and Penaeus monodon peptidomes using transcriptome shotgun assembly sequence data. General and Comparative Endocrinology 206:235-254. doi: 10.1016/j.ygcen.2014.04.015.

Christie AE, 2016. Prediction of Scylla olivacea (Crustacea; Brachyura) peptide hormones using publicly accessible transcriptome shotgun assembly (TSA) sequences. General and Comparative Endocrinology 230-231:1-16. doi: 10.1016/j.ygcen.2016.03.008.

Christie AE, Chi M. 2015. Prediction of the neuropeptidomes of members of the Astacidea (Crustacea, Decapoda) using publicly accessible transcriptome shotgun assembly (TSA) sequence data. General and Comparative Endocrinology 224:38-60. doi: 10.1016/j.ygcen.2015.06.001.

Christie AE, Stemmler EA, Peguero B, Messinger DI, Provencher HL, Scheerlinck P, Hsu YW, Guiney ME, de la Iglesia HO, Dickinson PS. 2006. Identification, physiological actions, and distribution of VYRKPPFNGSIFamide (Val1)-SIFamide) in the stomatogastric nervous system of the American lobster Homarus americanus. Journal of Comparative Neurology 496:406-421. doi: 10.1002/cne.20932.

Christie AE, Cashman CR, Brennan HR, Ma M, Sousa GL, Li L, Stemmler EA, Dickinson PS. 2008. Identification of putative crustacean neuropeptides using in silico analyses of publicly accessible expressed sequence tags. General and Comparative Endocrinology 156:246-64. doi: 10.1016/j.ygcen.2008.01.018.

Christie AE, Kutz-Naber KK, Stemmler EA, Klein A, Messinger DI, Goiney CC, Conterato AJ, Bruns EA, Hsu YW, Li L, Dickinson PS. 2007. Midgut epithelial endocrine cells are a rich source of the neuropeptides APSGFLGMRamide (Cancer borealis tachykinin-related peptide Ia) and GYRKPPFNGSIFamide (Gly1-SIFamide) in the crabs Cancer borealis, Cancer magister and Cancer productus. Journal of Experimental Biology 210):699-714. doi: 10.1242/jeb.02696.

Christie AE, Chi M, Lameyer TJ, Pascual MG, Shea DN, Stanhope ME, Schulz DJ, Dickinson PS. 2015. Neuropeptidergic signaling in the American lobster Homarus americanus: New insights from high-throughput nucleotide sequencing. PLoS One 10:e0145964. doi: 10.1371/journal.pone.0145964. 
754 Chung JS, Dircksen H, Webster SG. 1999. A remarkable, precisely timed release of

755 hyperglycemic hormone from endocrine cells in the gut is associated with ecdysis in the crab

756 Carcinus maenas. Proceedings of the National Academy of Sciences of the United States of

757

758

759

760

761

762

763

764

765

766

767

768

769

770

771

772

773

774

775

776

777

778

779

780

781

782

783

784

785

786

787

788

789

790

791

792

793

794

795

796

797

798

799

Chung JS, Wilcockson DC, Zmora N, Zohar Y, Dircksen H, Webster SG. 2006. Identification and developmental expression of mRNAs encoding crustacean cardioactive peptide (CCAP) in decapod crustaceans. Journal of Experimental Biology 209:3862-3872. doi: 10.1242/jeb.02425.

Colombani J, Andersen DS, Léopold P. 2012. Secreted peptide Dilp8 coordinates Drosophila tissue growth with developmental timing. Science 336:582-585. doi: 10.1126/science.1216689.

Cui Z, Hui M, Liu Y, Song C, Li X, Li Y, Liu L, Shi G, Wang S, Li F, Zhang X, Liu C, Xiang J, Chu KH. 2015. High-density linkage mapping aided by transcriptomics documents ZW sex determination system in the Chinese mitten crab Eriocheir sinensis. Heredity (Edinburgh) 115:206-215. doi: 10.1038/hdy.2015.26.

Derst C, Dircksen H, Meusemann K, Zhou X, Liu S, Predel R. 2016. Evolution of neuropeptides in non-pterygote hexapods. BMC Evolutionary Biology 16:51. doi: 10.1186/s12862-016-0621-4.

Dhara A, Eum JH, Robertson A, Gulia-Nuss M, Vogel KJ, Clark KD, Graf R, Brown MR, Strand MR. 2013. Ovary ecdysteroidogenic hormone functions independently of the insulin receptor in the yellow fever mosquito, Aedes aegypti. Insect Biochemistry and Molecular Biology 43:1100-1108. doi: 10.1016/j.ibmb.2013.09.004.

Dickinson PS, Stemmler EA, Cashman CR, Brennan HR, Dennison B, Huber KE, Peguero B, Rabacal W, Goiney CC, Smith CM, Towle DW, Christie AE. 2008. SIFamide peptides in clawed lobsters and freshwater crayfish (Crustacea, Decapoda, Astacidea): a combined molecular, mass spectrometric and electrophysiological investigation. General and Comparative Endocrinology 156:347-60. doi: 10.1016/j.ygcen.2008.01.011.

Dickinson PS, Stemmler EA, Barton EE, Cashman CR, Gardner NP, Rus S, Brennan HR, McClintock TS, Christie AE. 2009a. Molecular, mass spectral, and physiological analyses of orcokinins and orcokinin precursor-related peptides in the lobster Homarus americanus and the crayfish Procambarus clarkii. Peptides 30:297-317. doi: 10.1016/j.peptides.2008.10.009.

Dickinson PS, Wiwatpanit T, Gabranski ER, Ackerman RJ, Stevens JS, Cashman CR, Stemmler EA, Christie AE. 2009b. Identification of SYWKQCAFNAVSCFamide: a broadly conserved crustacean C-type allatostatin-like peptide with both neuromodulatory and cardioactive properties. Journal of Experimental Biology 212:1140-52. doi: 10.1242/jeb.028621.

Dircksen H, Böcking D, Heyn U, Mandel C, Chung JS, Baggerman G, Verhaert P, Daufeldt S, Plosch T, Jaros PP, Waelkens E, Keller R, Webster SG. 2001. Crustacean hyperglycaemic hormone $(\mathrm{CHH})$-like peptides and $\mathrm{CHH}$-precursor-related peptides from pericardial organ neurosecretory cells in the shore crab, Carcinus maenas, are putatively spliced and modified products of multiple genes. Biochemical Journal 356:159-170. doi: 10.1042/bj3560159. 
800

801

802

803

804

805

806

807

808

809

810

811

812

813

814

815

816

817

818

819

820

821

822

823

824

825

826

827

828

829

830

831

832

833

834

835

836

837

838

839

840

841

842

843

844

845

Dircksen H, Neupert S, Predel R, Verleyen P, Huybrechts J, Strauss J, Hauser F, Stafflinger E, Schneider M, Pauwels K, Schoofs L, Grimmelikhuijzen CJP. 2011. Genomics, transcriptomics, and peptidomics of Daphnia pulex neuropeptides and protein hormones. Journal of Proteome Research 10:4478-1504. doi: 10.1021/pr200284e.

Dissous C. 2015. Venus kinase receptors at the crossroads of insulin signaling: Their role in reproduction for helminths and insects. Frontiers in Endocrinology (Lausanne) 6:118. doi: 10.3389/fendo.2015.00118.

Du YX, Ma KY, Qiu GF. 2015. Discovery of the genes in putative GnRH signaling pathway with focus on characterization of GnRH-like receptor transcripts in the brain and ovary of the oriental river prawn Macrobrachium nipponense. Aquaculture 442:1-11.

doi:10.1016/j.aquaculture.2015.02.016.

Duve H, Johnsen AH, Maestro JL, Scott AG, Jaros PP, Thorpe A. 1997. Isolation and identification of multiple neuropeptides of the allatostatin superfamily in the shore crab Carcinus maenas. European Journal of Biochemistry 250:727-734. doi: 10.1111/j.14321033.1997.00727.x

Gao J, Wang X, Zou Z, Jia X, Wang Y, Zhang Z. 2014. Transcriptome analysis of the differences in gene expression between testis and ovary in green mud crab (Scylla paramamosain). BMC Genomics 15:585. doi: 10.1186/1471-2164-15-585.

Gao Y, Zhang X, Wei J, Sun X, Yuan J, Li F, Xiang J. 2015. Whole transcriptome analysis provides insights into molecular mechanisms for molting in Litopenaeus vannamei. PLoS One 10:e0144350. doi: 10.1371/journal.pone.0144350.

Garelli A, Gontijo AM, Miguela V, Caparros E, Dominguez M. 2012. Imaginal discs secrete insulin-like peptide 8 to mediate plasticity of growth and maturation. Science 336:579-582. doi: $10.1126 /$ science. 1216735 .

Garelli A, Heredia F, Casimiro AP, Macedo A, Nunes C, Garcez M, Dias AR, Volonte YA, Uhlmann T, Caparros E, Koyama T, Gontijo AM. 2015. Dilp8 requires the neuronal relaxin receptor Lgr3 to couple growth to developmental timing. Nature Commununications 6:8732. doi: $10.1038 /$ ncomms 9732 .

Ghaffari, Noushin; Sanchez-Flores, Alejandro; Ryan, Doan; Garcia-Orozco, Karina D; Chen, Patricia L.; Ochoa-Leyva, Adrian; Lopez-Zavala, Alonso A.; Carrasco, J. Salvador; Hong, Chris; Brieba, Luis G.; Rudino-Pinera, Enrique; Blood, Philip D.; Jason A., Sawyer; Johnson, Charles D.; Dindot, Scott V.; Sotelo-Mundo, Rogerio R.; Criscitiello, Michael F. 2014. Novel transcriptome assembly and improved annotation of the whiteleg shrimp (Litopenaeus vannamei), a dominant crustacean in global seafood mariculture. Scientific Reports 4:7081 doi:10.1038/srep07081.

Girardie J, Bourême D, Couillaud F, Tamarelle M, Girardie A. 1987. Anti-juvenile effect of 
846 neuroparsin A, a neuroprotein isolated from locust corpora cardiaca. Insect Biochemistry 17:977847 983. doi:10.1016/0020-1790(87)90106-5.

848

849 Girardie J, Girardie A, Huet JC, Pernollet JC. 1989. Amino acid sequence of locust neuroparsins.

850 FEBS Letters 245:4-8. doi: 10.1016/0014-5793(89)80179-6.

851

852 Gouy M, Guindon S, Gascuel O. 2010. SeaView version 4: A multiplatform graphical user

853

854

855

856

857

858

859

860

861

862

863

864

865

866

867

868

869

870

871

872

873

874

875

876

877

878

879

880 interface for sequence alignment and phylogenetic tree building. Molecular Biology and Evolution 27:221-4. doi: 10.1093/molbev/msp259.

Grabherr MG, Haas BJ, Yassour M, Levin JZ, Thompson DA, Amit I, Adiconis X, Fan L, Raychowdhury R, Zeng Q, Chen Z, Mauceli E, Hacohen N, Gnirke A, Rhind N, di Palma F, Birren BW, Nusbaum C, Lindblad-Toh K, Friedman N, Regev A. 2011. Full-length transcriptome assembly from RNA-Seq data without a reference genome. Nature Biotechnology 29:644-652. doi: 10.1038/nbt.1883.

Gu P-L, Chan SM. 1998. The shrimp hyperglycemic hormone-like neuropeptide is encoded by multiple copies of genes arranged in a cluster. FEBS Letters 441:397-403. doi: 10.1016/S00145793(98)01573-7

Gu P-L, Yu KL, Chan SM. 2000. Molecular characterization of an additional shrimp hyperglycemic hormone: cDNA cloning, gene organization, expression and biological assay of recombinant proteins. FEBS Letters 472:122-128. doi: 10.1016/S0014-5793(00)01420-4

Guan ZB, Shui Y, Liao XR, Xu ZH, Zhou X. 2014. Primary structure of a novel gonadotropinreleasing hormone $(\mathrm{GnRH})$ in the ovary of red swamp crayfish Procambarus clarkii. Aquaculture (418-419):67-71. tdoi: 10.1016/j.aquaculture.2013.10.010.

He L, Wang Q, Jin X, Wang Y, Chen L, Liu L, Wang Y. 2012. Transcriptome profiling of testis during sexual maturation stages in Eriocheir sinensis using Illumina sequencing. PLoS One 7:e33735. doi: 10.1371/journal.pone.0033735.

Hedges SB, Marin J, Suleski M, Paymer M, Kumar S. 2015. Tree of life reveals clock-like speciation and diversification. Molecular Biology and Evolution 32:835-845. doi: 10.1093/molbev/msv037.

881

882

883

884

885

886

887

888

889

890

Hsu YW, Messinger DI, Chung JS, Webster SG, de la Iglesia HO, Christie AE. 2006. Members of the crustacean hyperglycemic hormone $(\mathrm{CHH})$ peptide family are differentially distributed both between and within the neuroendocrine organs of Cancer crabs: implications for differential release and pleiotropic function. Journal of Experimental Biology 209:3241-3256. doi: 10.1242/jeb.02372.

Hsu YW, Stemmler EA, Messinger DI, Dickinson PS, Christie AE, de la Iglesia HO. 2010. Cloning and differential expression of two beta-pigment-dispersing hormone (beta-PDH) isoforms in the crab Cancer productus: evidence for authentic beta-PDH as a local 891 neurotransmitter and beta-PDH II as a humoral factor. Journal of Comparative Neurology 
892

893

894

895

896

897

898

899

900

901

902

903

904

905

906

907

908

909

910

911

912

913

914

915

916

917

918

919

920

921

922

923

924

925

926

927

928

929

930

931

932

933

934

935

936

937

508:197-211. doi: 10.1002/cne.21659.

Huang X, Ye H, Huang H, Yang Y, Gong J. 2014. An insulin-like androgenic gland hormone gene in the mud crab, Scylla paramamosain, extensively expressed and involved in the processes of growth and female reproduction. General and Comparative Endocrinology 204:229-38. doi: 10.1016/j.ygcen.2014.06.002.

Hui L, Xiang F, Zhang Y, Li L. 2012. Mass spectrometric elucidation of the neuropeptidome of a crustacean neuroendocrine organ. Peptides 36:230-9. doi: 10.1016/j.peptides.2012.05.007.

Hui M, Liu Y, Song C, Li Y, Shi G, Cui Z. 2014. Transcriptome changes in Eriocheir sinensis megalopae after desalination provide insights into osmoregulation and stress adaption in larvae. Transcriptome changes in Eriocheir sinensis megalopae after desalination provide insights into osmoregulation and stress adaption in larvae. PLoS One 9:e114187. doi:

10.1371/journal.pone.0114187.

Jiang H, Xing Z, Lu W, Qian Z, Yu H, Li J. 2014. Transcriptome analysis of red swamp crawfish Procambarus clarkii reveals genes involved in gonadal development. PLoS One 9:e105122. doi: 10.1371/journal.pone.0105122.

Jung H, Lyons RE, Dinh H, Hurwood DA, McWilliam S, Mather PB. 2011. Transcriptomics of a giant freshwater prawn (Macrobrachium rosenbergii): de novo assembly, annotation and marker discovery. PLoS One 6:e27938. doi: 10.1371/journal.pone.0027938.

Kegel G, Reichwein B, Weese S, Gaus G, Peter-Katalinić J, Keller R. 1989 .Amino acid sequence of the crustacean hyperglycemic hormone $(\mathrm{CHH})$ from the shore crab, Carcinus maenas. FEBS Letters 255:10-14. doi: 10.1111/j.1471-4159.1987.tb02902.x

Kim YJ, Bartalska K, Audsley N, Yamanaka N, Yapici N, Lee JY, Kim YC, Markovic M, Isaac E, Tanaka Y, Dickson BJ. 2010. MIPs are ancestral ligands for the sex peptide receptor.

Proceedings of the National Academy of Sciences of the United States of America 107:65206525. doi: 10.1073/pnas.0914764107.

Klein JM, de Kleijn DP, Keller R, Weidemann WM. 1992. Molecular cloning of crustacean pigment dispersing hormone precursor. Biochemical and Biophysical Research

Commununications 189:1509-1514. doi:10.1016/0006-291X(92)90246-H.

Klein JM, Mangerich S, de Kleijn DP, Keller R, Weidemann,W.M. 1993. Molecular cloning of crustacean putative molt-inhibiting hormone (MIH) precursor. FEBS Letters 334:139-142. doi: 10.1016/0014-5793(93)81699-Z.

Li S, Li F, Wang B, Xie Y, Wen R, Xiang J. 2010. Cloning and expression profiles of two isoforms of a CHH-like gene specifically expressed in male Chinese shrimp, Fenneropenaeus chinensis. General and Comparative Endocrinology 167:308-316.

doi:10.1016/j.ygcen.2010.03.028. 
938

939

940

941

942

943

944

945

946

947

948

949

950

951

952

953

954

955

956

957

958

959

960

961

962

963

964

965

966

967

968

969

970

971

972

973

974

975

976

977

978

979

980

981

982

983

Li C, Weng S, Chen Y, Yu X, Lü L, Zhang H, He J, Xu X. 2012. Analysis of Litopenaeus vannamei transcriptome using the next-generation DNA sequencing technique. PLoS One 7:e47442. doi: 10.1371/journal.pone.0047442.

Li Y, Hui M, Cui Z, Liu Y, Song C, Shi G. 2014. Comparative transcriptomic analysis provides insights into the molecular basis of the metamorphosis and nutrition metabolism change from zoeae to megalopae in Eriocheir sinensis. Comparative Biochemistry and Physiology Part D Genomics and Proteomics 13:1-9. doi: 10.1016/j.cbd.2014.10.002.

Linck B, Klein JM, Mangerich S, Keller R, Weidemann WM . 1993. Molecular cloning of crustacean red pigment concentrating hormone precursor. Biochemical and Biophysical Research Commununications 195:807-813. doi:10.1006/bbrc.1993.2117.

Linneweber GA, Jacobson J, Busch KE, Hudry B, Christov CP, Dormann D, Yuan M, Otani T, Knust E, de Bono M, Miguel-Aliaga I. 2014. Neuronal control of metabolism through nutrientdependent modulation of tracheal branching. Cell 156:69-83. doi: 10.1016/j.cell.2013.12.008.

Liu Y, Hui M, Cui Z, Luo D, Song C, Li Y, Liu L. 2015. Comparative transcriptome analysis reveals sex-biased gene expression in juvenile Chinese mitten crab Eriocheir sinensis. PLoS One 10:e0133068. doi: 10.1371/journal.pone.0133068.

Lugo JM, Carpio Y, Morales R, Rodríguez-Ramos T, Ramos L, Estrada MP. 2013. First report of the pituitary adenylate cyclase activating polypeptide (PACAP) in crustaceans: conservation of its functions as growth promoting factor and immunomodulator in the white shrimp Litopenaeus vannamei. Fish \& Shellfish Immunology 35:1788-96. doi: 10.1016/j.fsi.2013.08.028.

Luo X, Chen T, Zhong M, Jiang X, Zhang L, Ren C, Hu C. 2015. Differential regulation of hepatopancreatic vitellogenin (VTG) gene expression by two putative molt-inhibiting hormones (MIH1/2) in Pacific white shrimp (Litopenaeus vannamei). Peptides 68:58-63. doi: 10.1016/j.peptides.2014.11.002.

Ma M, Chen R, Sousa GL, Bors EK, Kwiatkowski MA, Goiney CC, Goy MF, Christie AE, Li L. 2008. Mass spectral characterization of peptide transmitters/hormones in the nervous system and neuroendocrine organs of the American lobster Homarus americanus. General and Comparative Endocrinology 156:395-409. doi: 10.1016/j.ygcen.2008.01.009.

Ma M, Bors EK, Dickinson ES, Kwiatkowski MA, Sousa GL, Henry RP, Smith CM, Towle DW, Christie AE, Li L. 2009. Characterization of the Carcinus maenas neuropeptidome by mass spectrometry and functional genomics. General and Comparative Endocrinology 161:320-334. doi: 10.1016/j.ygcen.2009.01.015.

Ma M, Gard AL, Xiang F, Wang J, Davoodian N, Lenz PH, Malecha SR, Christie AE, Li L. 2010. Combining in silico transcriptome mining and biological mass spectrometry for neuropeptide discovery in the Pacific white shrimp Litopenaeus vannamei. Peptides 31:27-43. doi: 10.1016/j.peptides.2009.10.007. 
984 Ma H, Ma C, Li S, Jiang W, Li X, Liu Y, Ma L. 2014. Transcriptome analysis of the mud crab 985 (Scylla paramamosain) by 454 deep sequencing: assembly, annotation, and marker discovery. 986 PLoS One 9:e102668. doi: 10.1371/journal.pone.0102668.

987

988

989

990

991

992

993

994

995

996

997

998

999

1000

1001

1002

1003

1004

1005

1006

1007

1008

1009

1010

1011

1012

1013

1014

1015

1016

1017

1018

1019

1020

1021

1022

1023

1024

1025

1026

1027

1028

1029
Manfrin C, Tom M, De Moro G, Gerdol M, Giulianini PG, Pallavicini A. 2015. The eyestalk transcriptome of red swamp crayfish Procambarus clarkii. Gene 557:28-34. doi:

10.1016/j.gene.2014.12.001.

Meissner GW, Luo SD, Dias BG, Texada MJ, Baker BS. 2016. Sex-specific regulation of Lgr3 in Drosophila neurons. Proceedings of the National Academy of Sciences of the United States of America 113:E1256-65. doi: 10.1073/pnas.1600241113.

Nässel DR, vanden Broeck J. 2015. Insulin/IGF signaling in Drosophila and other insects: factors that regulate production, release and post-release action of the insulin-like peptides. Cellular and Molecular Life Sciences 216:271-290. doi: 10.1007/s00018-015-2063-3.

Nuss AB, Forschler BT, Crim JW, TeBrugge V, Pohl J, Brown MR. 2010. Molecular characterization of neuropeptide $\mathrm{F}$ from the eastern subterranean termite Reticulitermes flavipes (Kollar) (Isoptera: Rhinotermitidae). Peptides 31:419-428. doi: 10.1016/j.peptides.2009.09.001.

Ohler U. 2006. Identification of core promoter modules in Drosophila and their application in accurate transcription start site prediction. Nucleic Acids Research 34:5943-5950. doi: 10.1093/nar/gkl608.

Ollivaux C, Vinh J, Soyez D, Toullec JY. 2006. Crustacean hyperglycemic and vitellogenesisinhibiting hormones in the lobster Homarus gammarus. FEBS Journal 273,2151-2160. doi: 10.1111/j.1742-4658.2006.05228.x.

Paluzzi JP, Vanderveken M, O'Donnell MJ. 2014. The heterodimeric glycoprotein hormone, GPA2/GPB5, regulates ion transport across the hindgut of the adult mosquito, Aedes aegypti. PLoS One 9:e86386. doi: 10.1371/journal.pone.0086386.

Parnes S, Khalaila I, Hulata G, Sagi A, 2003. Sex determination in crayfish: are intersex Cherax quadricarinatus (Decapoda, Parastacidae) genetically females? Genetics Research 82:107-116. doi: $10.1017 /$ S0016672303006372

Peng J, Wei P, Zhang B, Zhao Y, Zeng D, Chen X, Li M, Chen X. 2015. Gonadal transcriptomic analysis and differentially expressed genes in the testis and ovary of the Pacific white shrimp (Litopenaeus vannamei). BMC Genomics 16:1006. doi: 10.1186/s12864-015-2219-4.

Price MN, Dehal PS, Arkin AP. 2010. FastTree 2--approximately maximum-likelihood trees for large alignments. PLoS One 5:e9490. doi: 10.1371/journal.pone.0009490.

Richards S, Murali SC. 2015. Best practices in insect genome sequencing: what works and what doesn't. Current Opinion in Insect Science 7:1-7. doi:

10.1016/j.cois.2015.02.013. 
1030

1031

1032

1033

1034

1035

1036

1037

1038

1039

1040

1041

1042

1043

1044

1045

1046

1047

1048

1049

1050

1051

1052

1053

1054

1055

1056

1057

1058

1059

1060

1061

1062

1063

1064

1065

1066

1067

1068

1069

1070

1071

1072

1073

1074

1075

Roller L, Yamanaka N, Watanabe K, Daubnerová I, Zitnan D, Kataoka H, Tanaka Y. 2008. The unique evolution of neuropeptide genes in the silkworm Bombyx mori. Insect Biochemistry and Molecular Biology 38:1147-1157. doi:10.1016/j.ibmb.2008.04.009.

Roller L, Zitnanová I, Dai L, Simo L, Park Y, Satake H, Tanaka Y, Adams ME, Zitnan D. 2010. Ecdysis triggering hormone signaling in arthropods. Peptides 31:429-41. doi:

10.1016/j.peptides.2009.11.022.

Satchell L, Glister C, Bleach EC, Glencross RG, Bicknell AB, Dai Y, Anand-Ivell R, Ivell R, Knight PG. 2013. Ovarian expression of insulin-like peptide 3 (INSL3) and its receptor (RXFP2) during development of bovine antral follicles and corpora lutea and measurement of circulating INSL3 levels during synchronized estrous cycles. Endocrinology 154:1897-906. doi: 10.1210/en.2012-2232.

Sellami A, Agricola HJ, Veenstra JA. 2011. Neuroendocrine cells in Drosophila melanogaster producing GPA2/GPB5, a hormone with homology to LH, FSH and TSH. General and Comparative Endocrinology 170:582-588. doi: 10.1016/j.ygcen.2010.11.015.

Sharabi O, Manor R, Weil S, Aflalo ED, Lezer Y, Levy T, Aizen J, Ventura T, Mather PB, Khalaila I, Sagi A. 2016. Identification and characterization of an insulin-like receptor involved in crustacean reproduction. Endocrinology 157:928-941. doi: 10.1210/en.2015-1391.

Shen H, Hu Y, Ma Y, Zhou X, Xu Z, Shui Y, Li C, Xu P, Sun X. 2014. In-depth transcriptome analysis of the red swamp crayfish Procambarus clarkii. PLoS One 9:e110548. doi: 10.1371/journal.pone.0110548.

Sievers F, Wilm A, Dineen D, Gibson TJ, Karplus K, Li W, Lopez R, McWilliam H, Remmert M, Söding J, Thompson JD, Higgins DG. 2011. Fast, scalable generation of high-quality protein multiple sequence alignments using Clustal Omega. Molecular Systems Biology 7:539. doi: $10.1038 / \mathrm{msb} .2011 .75$.

Song C, Cui Z, Hui M, Liu Y, Li Y, Li X. 2015. Comparative transcriptomic analysis provides insights into the molecular basis of brachyurization and adaptation to benthic lifestyle in Eriocheir sinensis. Gene 558:88-98. doi: 10.1016/j.gene.2014.12.048.

Song L, Bian C, Luo Y, Wang L, You X, Li J, Qiu Y, Ma X, Zhu Z, Ma L, Wang Z, Lei Y, Qiang J, Li H, Yu J, Wong A, Xu J, Shi Q, Xu P. 2016. Draft genome of the Chinese mitten crab, Eriocheir sinensis. Gigascience 5:5. doi: 10.1186/s13742-016-0112-y.

Staelens J, Rombaut D, Vercauteren I, Argue B, Benzie J, Vuylsteke M, 2008. High-density linkage maps and sex-linked markers for the black tiger shrimp (Penaeus monodon). Genetics 179 :917-925. doi: 10.1534/genetics.107.080150.

Stangier J, Hilbich C, Beyreuther K, Keller R. 1987. Unusual cardioactive peptide (CCAP) from pericardial organs of the shore crab Carcinus maenas. Proceedings of the National Academy of 
1076

1077

1078

1079

1080

1081

1082

1083

1084

1085

1086

1087

1088

1089

1090

1091

1092

1093

1094

1095

1096

1097

1098

1099

1100

1101

1102

1103

1104

1105

1106

1107

1108

1109

1110

1111

1112

1113

1114

1115

1116

1117

1118

1119

1120

1121

Sciences of the United States of America 84:575-579.

Stangier J, Hilbich C, Burdzik S, Keller R. 1992. Orcokinin: a novel myotropic peptide from the nervous system of the crayfish, Orconectes limosus. Peptides 13:859-864. doi:10.1016/01969781(92)90041-Z.

Stemmler EA, Bruns EA, Gardner NP, Dickinson PS, Christie AE. 2007a. Mass spectrometric identification of pEGFYSQRYamide: a crustacean peptide hormone possessing a vertebrate neuropeptide Y (NPY)-like carboxy-terminus. General and Comparative Endocrinology 152:17.

Stemmler EA, Cashman CR, Messinger DI, Gardner NP, Dickinson PS, Christie AE. 2007b. High-mass-resolution direct-tissue MALDI-FTMS reveals broad conservation of three neuropeptides (APSGFLGMRamide, GYRKPPFNGSIFamide and pQDLDHVFLRFamide) across members of seven decapod crustaean infraorders. Peptides 28:2104-15.

Stemmler EA, Bruns EA, Cashman CR, Dickinson PS, Christie AE. 2010. Molecular and mass spectral identification of the broadly conserved decapod crustacean neuropeptide pQIRYHQCYFNPISCF: the first PISCF-allatostatin (Manduca sexta- or C-type allatostatin) from a non-insect. General and Comparative Endocrinology 165:1-10. doi: 10.1016/j.ygcen.2009.05.010.

Sturm S, Ramesh D, Brockmann A, Neupert S, Predel R. 2016. Agatoxin-like peptides in the neuroendocrine system of the honey bee and other insects. Journal of Proteomics 132:77-84. doi: 10.1016/j.jprot.2015.11.021.

Sun Y, Zhang Y, Liu Y, Xue S, Geng X, Hao T, Sun J. 2014. Changes in the organics metabolism in the hepatopancreas induced by eyestalk ablation of the Chinese mitten crab Eriocheir sinensis determined via transcriptome and DGE analysis. PLoS One 9:e95827. doi: 10.1371/journal.pone.0095827.

Suwansa-Ard S, Thongbuakaew T, Wang T, Zhao M, Elizur A, Hanna PJ, Sretarugsa P, Cummins SF, Sobhon P. 2015. In silico neuropeptidome of female Macrobrachium rosenbergii based on transcriptome and peptide mining of eyestalk, central nervous system and ovary. PLoS One 10:e0123848. doi: 10.1371/journal.pone.0123848.

Tanaka Y, Suetsugu Y, Yamamoto K, Noda H, Shinoda T. 2014. Transcriptome analysis of neuropeptides and G-protein coupled receptors (GPCRs) for neuropeptides in the brown planthopper Nilaparvata lugens. Peptides 53:125-33. doi: 10.1016/j.peptides.2013.07.027.

Thongbuakaew T, Saetan J, Suwansa-ard A, Kankoun W, Sumpownon C, Parhar I, Meeratana P, Sobhon P, Sretarugsa P. 2016. The existence of kisspeptin-like peptides and effects on ovarian development and maturation in the giant freshwater prawn Macrobrachium rosenbergii. Aquaculture 455:50-62. doi: 10.1016/j.aquaculture.2016.01.006.

Tom M, Manfrin C, Chung SJ, Sagi A, Gerdol M, De Moro G, Pallavicini A, Giulianini PG. 
1122 2014. Expression of cytoskeletal and molt-related genes is temporally scheduled in the 1123 hypodermis of the crayfish Procambarus clarkii during premolt. Journal of Experimental

1124 Biology 217:4193-202. doi: 10.1242/jeb.109009.

1125

1126

1127

Toullec JY, Corre E, Bernay B, Thorne MA, Cascella K, Ollivaux C, Henry J, Clark MS. 2013.

1128 Transcriptome and peptidome characterisation of the main neuropeptides and peptidic hormones of a euphausiid: the Ice Krill, Euphausia crystallorophias. PLoS One 8:e71609. doi:

1129

1130

1131 10.1371/journal.pone.0071609.

1132

Vallejo DM, Juarez-Carreño S, Bolivar J, Morante J, Dominguez M. 2015. A brain circuit that

1133 synchronizes growth and maturation revealed through Dilp8 binding to Lgr3. Science

1134

1135 350:aac6767. doi: 10.1126/science.aac6767.

1136

Vanderstraete M, Gouignard N, Ahier A, Morel M, Vicogne J, Dissous C. 2013. The venus kinase receptor (VKR) family: structure and evolution. BMC Genomics 14:361. doi:

1137 10.1186/1471-2164-14-361.

1138

1139

1140

Veenstra JA. 2000. Mono- and dibasic proteolytic cleavage sites in insect neuroendocrine peptide precursors. Archives of Insect Biochemistry and Physiology 43:49-63. doi: 10.1002/(SICI)1520-6327(200002)43:2<49::AID-ARCH1>3.0.CO;2-M.

1144

Veenstra JA. 2010a. Neurohormones and neuropeptides encoded by the genome of Lottia gigantea, with reference to other mollusks and insects. General and Comparative Endocrinology 167:86-103. doi: 10.1016/j.ygcen.

1146

Veenstra JA. 2010b. What the loss of the hormone neuroparsin in the melanogaster subgroup of Drosophila can tell us about its function. Insect Biochemistry and Molecular Biology 40,354-61. doi: 10.1016/j.ibmb.2010.03.001.

1152

Veenstra JA. 2011. Neuropeptide evolution: neurohormones and neuropeptides predicted from

1153

1154 the genomes of Capitella teleta and Helobdella robusta. General and Comparative Endocrinology 171:160-175. doi: 10.1016/j.ygcen.2011.01.005.

Veenstra JA. 2014. The contribution of the genomes of a termite and a locust to our understanding of insect neuropeptides and neurohormones. Frontiers in Physiology 5:454. doi:

1157 10.3389/fphys.2014.00454.

1158

Veenstra JA. 2015. The power of next-generation sequencing as illustrated by the neuropeptidome of the crayfish Procambarus clarkii. General and Comparative Endocrinology 224:84-95. doi: 10.1016/j.ygcen.2015.06.013. 229:41-55. doi: 10.1016/j.ygcen.2015.11.019.

1167 Veenstra JA, Ida T. 2014. More Drosophila enteroendocrine peptides: Orcokinin B and the 
1168 CCHamides 1 and 2. Cell and Tissue Research 357:607-621. doi: 10.1007/s00441-014-1880-2.

1169

1170

1171

1172

1173

1174

1175

1176

1177

1178

1179

1180

1181

1182

1183

1184

1185

1186

1187

1188

1189

1190

1191

1192

1193

1194

1195

1196

1197

1198

1199

1200

1201

1202

1203

1204

1205

1206

1207

1208

1209

1210

1211

1212

1213
Veenstra JA, Rodriguez L, Weaver RJ. 2012. Allatotropin, leucokinin and AKH in honey bees and other Hymenoptera. Peptides 35,122-130. doi: 10.1016/j.peptides.2012.02.019.

Veenstra JA, Rombauts S, Grbić M. 2012. In silico cloning of genes encoding neuropeptides, neurohormones and their putative G-protein coupled receptors in a spider mite. Insect Biochemistry and Molecular Biology 42:277-295. doi: 10.1016/j.ibmb.2011.12.009.

Ventura T, Sagi A. 2012. The insulin-like androgenic gland hormone in crustaceans: From a single gene silencing to a wide array of sexual manipulation-based biotechnologies.

Biotechnology Advances 30:1543-50. doi: 10.1016/j.biotechadv.2012.04.008.

Ventura T, Manor R, Aflalo ED, Weil S, Raviv S, Glazer L, Sagi A. 2009. Temporal silencing of an androgenic gland-specific insulin-like gene affecting phenotypical gender differences and spermatogenesis. Endocrinology 150:1278-1286. doi: 10.1210/en.2008-0906.

Ventura T, Aflalo ED, Weil S, Kashkush K, Sagi A, 2011. Isolation and characterization of a female-specific DNA marker in the giant freshwater prawn Macrobrachium rosenbergii. Heredity (Edinburgh) 107:456-461. doi: 10.1038/hdy.2011.32.

Ventura T, Manor R, Aflalo ED, Chalifa-Caspi V, Weil S, Sharabi O, Sagi A. 2013. Postembryonic transcriptomes of the prawn Macrobrachium rosenbergii: multigenic succession through metamorphosis. PLoS One 8 :e55322. doi: 10.1371/journal.pone.0055322.

Ventura T, Cummins SF, Fitzgibbon Q, Battaglene S, Elizur A. 2014. Analysis of the central nervous system transcriptome of the eastern rock lobster Sagmariasus verreauxi reveals its putative neuropeptidome. PLoS One 9:e97323. doi: 10.1371/journal.pone.0097323.

Ventura-López C, Gómez-Anduro G, Arcos FG, Llera-Herrera R, Racotta IS, Ibarra AM. 2016. A novel CHH gene from the Pacific white shrimp Litopenaeus vannamei was characterized and found highly expressed in gut and less in eyestalk and other extra-eyestalk tissues. Gene 582:148-160. doi: 10.1016/j.gene.2016.02.011.

Verbruggen B, Bickley LK, Santos EM, Tyler CR, Stentiford GD, Bateman KS, van Aerle R. 2015. De novo assembly of the Carcinus maenas transcriptome and characterization of innate immune system pathways. BMC Genomics 16:458. doi: 10.1186/s12864-015-1667-1.

Vogel KJ, Brown MR, Strand MR. 2015. Ovary ecdysteroidogenic hormone requires a receptor tyrosine kinase to activate egg formation in the mosquito Aedes aegypti. Proceedings of the National Academy of Sciences of the United States of America 112:5057-62. doi: 10.1073/pnas. 1501814112.

Wang B, Ning Q, Hao T, Yu A, Sun J. 2016. Reconstruction and analysis of a genome-scale metabolic model for Eriocheir sinensis eyestalks. Molecular BioSystems 12:246-252. doi: $10.1039 / \mathrm{c} 5 \mathrm{mb} 00571 \mathrm{j}$. 
1214

1215

1216

1217

1218

1219

1220

1221

1222

1223

1224

1225

1226

1227

1228

1229

1230

1231

1232

1233

1234

1235

1236

1237

1238

1239

1240

1241

1242

1243

1244

1245

1246

1247

1248

1249

1250
Webster SG, Keller R, Dircksen H. 2012. The CHH-superfamily of multifunctional peptide hormones controlling crustacean metabolism, osmoregulation, moulting, and reproduction. General and Comparative Endocrinology 175:217-233. doi: 10.1016/j.ygcen.2011.11.035.

Wei J, Zhang X, Yu Y, Li F, Xiang J. 2014. RNA-Seq reveals the dynamic and diverse features of digestive enzymes during early development of Pacific white shrimp Litopenaeus vannamei. Comparative Biochemistry and Physiology Part D: Genomics and Proteomics 11:37-44. doi: 10.1016/j.cbd.2014.07.001.

Wilcockson DC, Webster SG. 2008. Identification and developmental expression of mRNAs encoding putative insect cuticle hardening hormone, bursicon in the green shore crab Carcinus maenas. General and Comparative Endocrinology 156:113-125. doi:10.1016/j.ygcen.2007.12.003.

Worden MK, Kravitz EA, Goy MF. 1995. Peptide F1, an N-terminally extended analog of FMRFamide, enhances contractile activity in multiple target tissues in lobster. Journal of Experimental Biology 198:97-108.

Xu Z, Zhao M, Li X, Lu Q, Li Y, Ge J, Pan J. 2015. Transcriptome profiling of the eyestalk of precocious juvenile Chinese mitten crab reveals putative neuropeptides and differentially expressed genes. Gene 569:280-286. doi: 10.1016/j.gene.2015.05.075.

Yang SP, He JG, Sun CB, Chan SF. 2014. Characterization of the shrimp neuroparsin (MeNPLP): RNAi silencing resulted in inhibition of vitellogenesis. FEBS Open Biology 4:97686. doi: 10.1016/j.fob.2014.09.005.

Yu Y, Zhang X, Yuan J, Li F, Chen X, Zhao Y, Huang L, Zheng H, Xiang J. 2015. Genome survey and high-density genetic map construction provide genomic and genetic resources for the Pacific white shrimp Litopenaeus vannamei. Scientific Reports 5:15612. doi: 10.1038/srep15612.

Zmora N, Chung JS. 2014. A novel hormone is required for the development of reproductive phenotypes in adult female crabs. Endocrinology 155:230-239. doi: 10.1210/en.2013-1603. 


\section{Figure 1 (on next page)}

Overview of the presence neuropeptide genes in seven decapods, Daphnia pulex and two insect species.

Dark blue: neuropeptide precursors that have been published previously; light blue, neuropeptide precursors (or significant parts therefore) that can be deduced directly from publicly available TSAs; red: precursors assembled here; yellow: precursors that could not be assembled, but for which individual reads in TSAs demonstrate their existence in the particular species. Asterisks indicate the existence of more than one gene. 


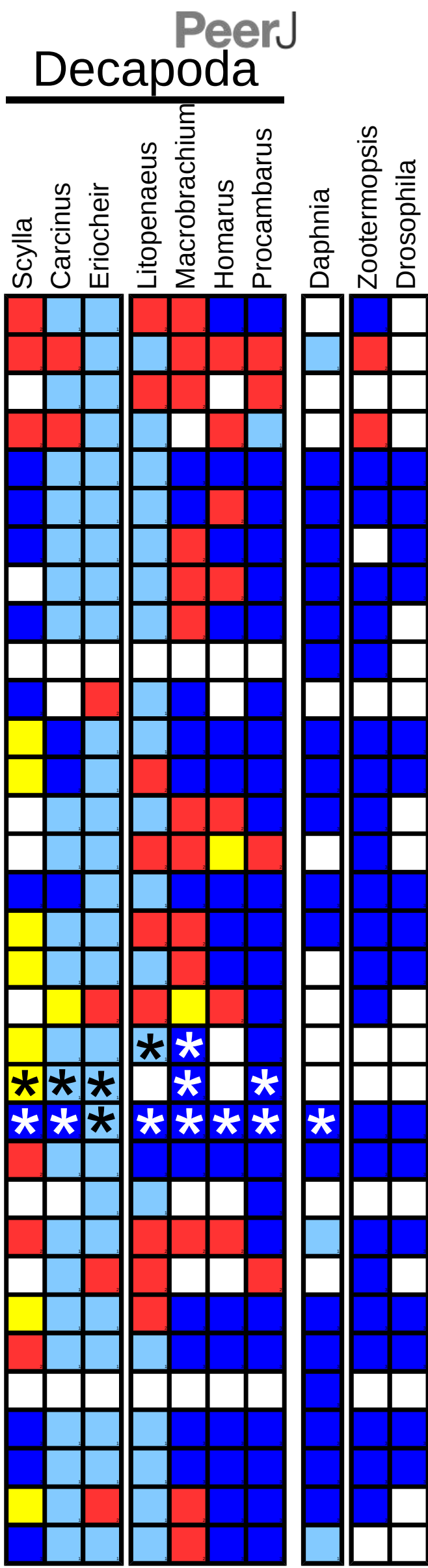

$\mathrm{ACP}$

Agatoxin-like a

Agatoxin-like $b$

Agatoxin-like $\mathrm{C}$

Allatostatin A

Allatostatin B

Allatostatin $C$

Allatostatin $\mathrm{CC}$

Allatostatin CCC

Allatotropin

Androgenic peptide

Bursicon A

Bursicon $B$

Calcitonin a

Calcitonin b

CCAP

CCHamide 1

CCHamide 2

CCRFamide

CFSH 1

CFSH 2

$\mathrm{CHH}$ (or ITP)

$\mathrm{CHH}$ alt last exon

$\mathrm{CHH}-\mathrm{MIH}$-like

CNMamide a

CNMamide $b$

Corazonin

CRF-like

DENamide

DH31

Eclosion hormone 1

Eclosion hormone 2

EFLamide
Manuscript to be reviewed

\section{Decapoda}

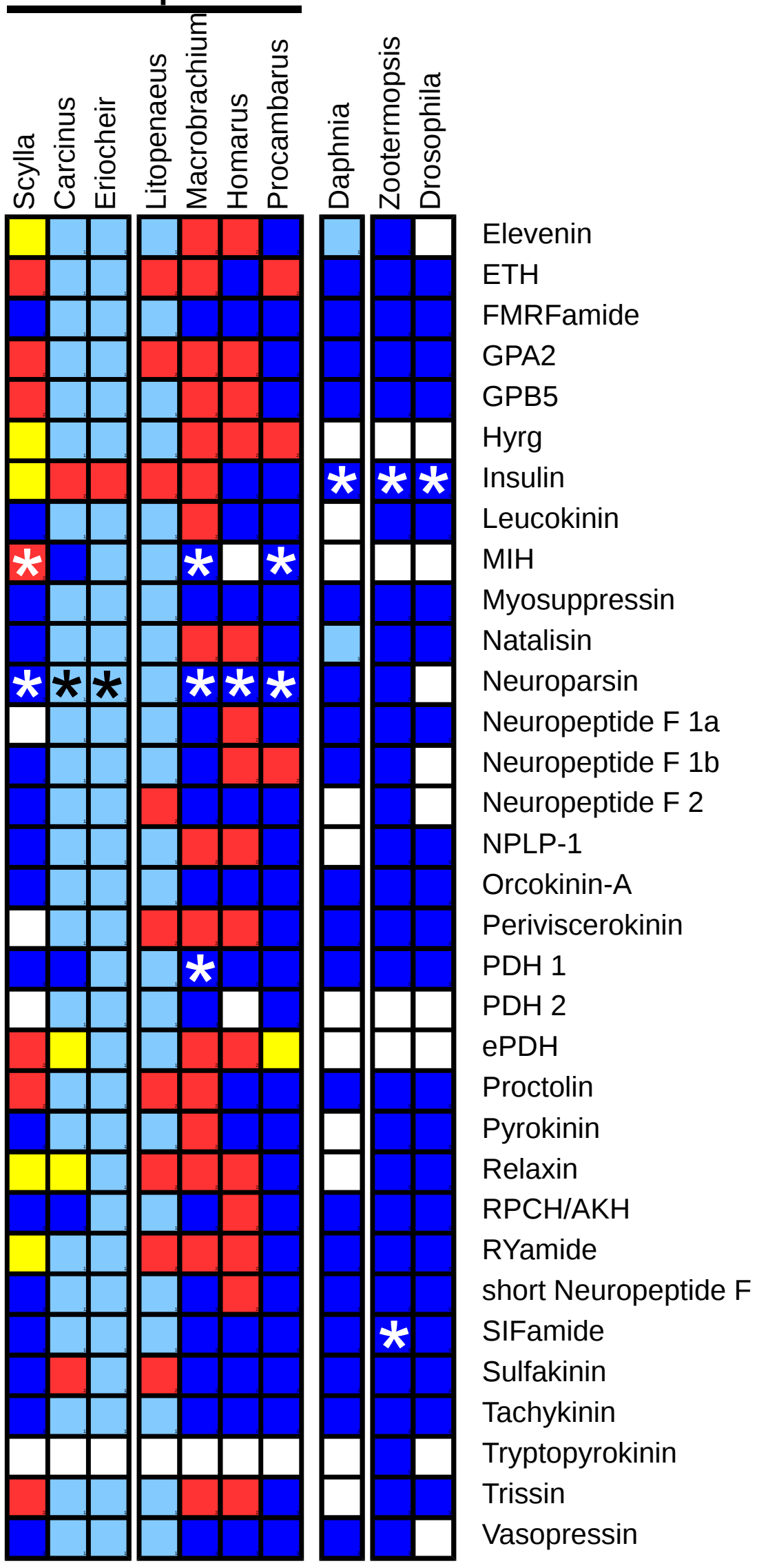




\section{Figure 2 (on next page)}

Sequence allignment of PDH and ePDH.

Parts of the various PDH precursors including the convertase cleavage sites of the various decapod species. Note that the ubiquitous presence of ePDH that has a two amino acid insertion. 


\section{Scylla}

Carcinus-1

Carcinus-2

Eriocheir-1

Eriocheir-2

Litopenaeus-1a

Litopenaeus-1b

Litopenaeus-2

Macrobrachium-1

Macrobrachium-2

Macrobrachium-3

Homarus

Procambarus-1

Procambarus-2
KRNSELINSILGLPKV- - MNDAGRR KRNSELINSILGLPKV - - MNDAGRR KRNSELINSLLGLSRM - - MTQAGRR KRNSELINSILGLPKV - - MNDAGRR KRNSEIINSLLGISKL - - MNEAGRR KRNSELINSLLGLPKV - - MNDAGR KRNSELINSLLGIPKV- - MNDAGRR KRNSELINSLLGLPKF - - MIDAGRR KRNSGMINSILGIPRV- - MAEAGKK KRNSGMINSLLGIPMV - - MAEAGKK KRNSELINSLLGLPKV - - MTDAGRR KRNSELINSILGLPKV - - MNDAGRR KRNSELINSILGLPKV - - MNEAGRR KRNSELINALLGSPTL - - MGEVGRK

\section{ePDH}

Scylla

Eriocheir

Carcinus

Homarus

Procambarus

Macrobrachium

Litopenareus"

KRNSELLNTLLGSQDLGNMRNAGRR KRNSELLNTLLGSQTLSNMRNAGRR KRNSELLNTLLGSQDLGNMRNAGRR KRNSEILNTLLGSQDLSNMRSAGRR KRNSELLNTLLGSQGLSNMRSAGRR KRNSEILNTLLGSGALSNMKINGRR

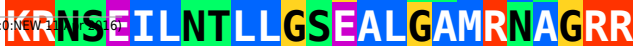




\section{Figure 3 (on next page)}

Structure of the ePDH gene from Eriocheir sinensis.

The ePDH gene consists of three exons and two introns. DNA sequences coding the signal peptide in yellow, mature ePDH sequence in red and the remainder of the precursor in blue. Numbers indicate sizes of introns and exons in nucleotides. The DNA sequence containing the TATA box and a sequence that is recognizably similar to the Drosophila core promoter

motif 1 (in blue, Ohler, 2006) and the start of the mRNA (in red) are also displayed; the red nucleotides at the end are part of the mRNA. 
Figure 4(on next page)

Phylogenetic tree showing the evolutionary relationships between the $\mathrm{CHH}$ and $\mathrm{MIH}$ hormones.

Hormones are those identified from decapod SRAs as well as a few for which the biological activity has been described. Highlighted in yellow are the four sequences that on the tree are more similar to $\mathrm{CHH}$, but lack the precursor-related peptide typically present in $\mathrm{CHH}$. 



\section{5}

CFSH alignments.

Note that the two types of CFSH are clearly different from one another. Scylla paramamosain is not included in the figure, as there are only a few individual reads from this species. These reads correspond to orthologs of the three crab CFSHs; those that correpond to $S$. paramamosain 2a predict a protein sequence that is completely identical to the $S$. olivacea sequence illustrated. 
Callinectes Portunus Eriocheir_1 Carcinus_ 1 Procambarus-1 Litopenaeus_1a Litopenaeus_1b Macrobrachium_1a Macrobrachium_1b Litopenaeus_1c Marsupenaeus

Scylla_olivacea Carcinus_2a Eriocheir_2a Macrobrachium-2a Procambarus_2a Procambarus_2b Macrobrachium_2b Erocheir_2b Carcinus_2b

Callinectes Portunus Eriocheir_1 Carcinus_1 Procambarus-1 Litopenaeus_1a Litopenaeus_1b Macrobrachium_1a Macrobrachium_1b Litopenaeus_1c Marsupenaeus

Scylla_olivacea Carcinus_2a Eriocheir_2a Macrobrachium-2a Procambarus_2a Procambarus_2b Macrobrachium_2b Erocheir_2b Carcinus_2b

Callinectes Portunus

Eriocheir_1

Carcinus_ 1

Procambarus-1 Litopenaeus_1a Litopenaeus_1b Macrobrachium_1a Macrobrachium_1b Litopenaeus_1c Marsupenaeus

Scylla_olivacea Carcinus_2a Eriocheir_2a Macrobrachium-2a Procambarus_2a Procambarus_2b Macrobrachium_2b Erocheir_2b Carcinus_2b

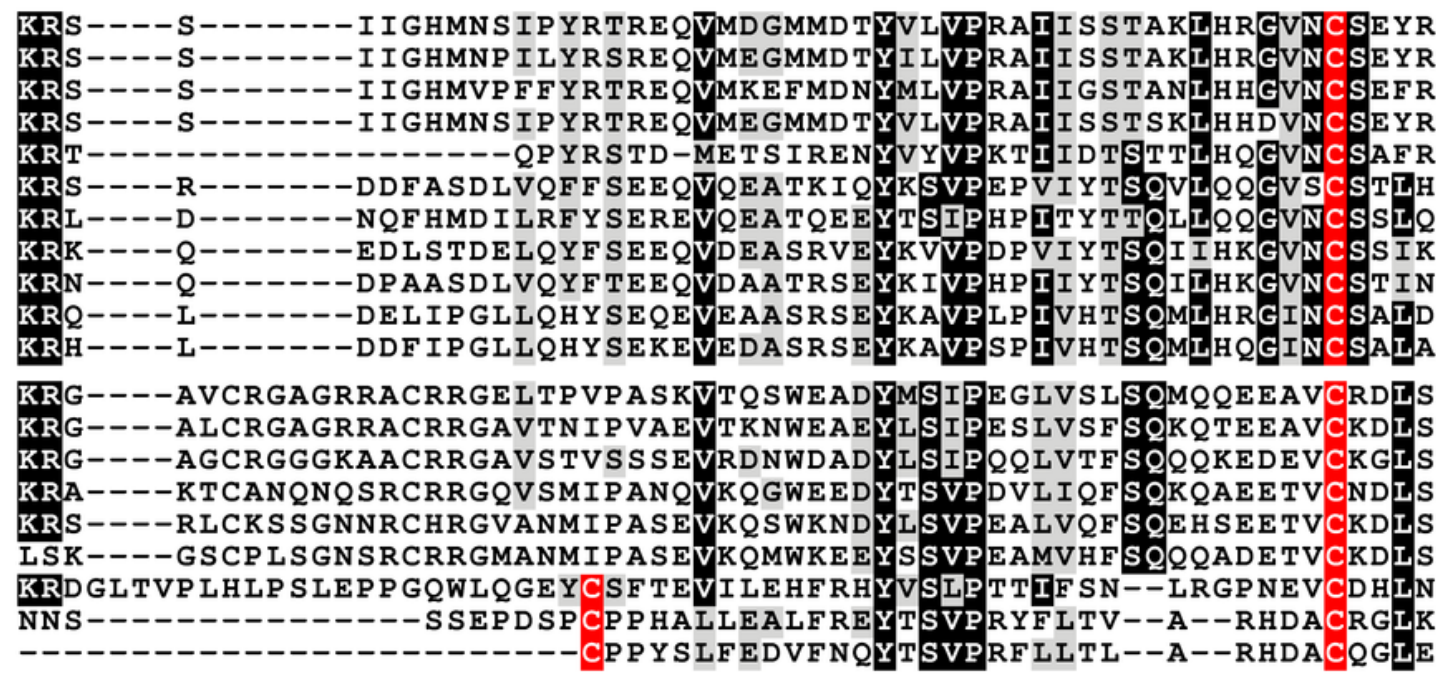

EVS KVYGNGF EANYNLRPTWP HRSK TIS TCPTQYVERQ I - QGP L P I QPVT I LEAKCVCEGSQC EVSKVYGNGF EANYNLRPTWLHRSKTVSTCP TQYIERQI-QGP LP I QPVT I LEAKCVCEGS QC EGSKVYENRF QANF SMRP IWL HRSETISTCP TQYVERQI QQGS LPVQPVTVLEAKCVCEGSQC EVNKIHGNRF EANFNIRPTWLHRSKTISTCPTQYVERQI-QGPF P I QPVTILEAKCVCEGSQC --VTHHVNTFTEELHRSPTWLHSSSMI GDCP TRYVKKNMNEP--IQYFPEILEAQCICEDSQC --SEMHENY I KP E LRLRPEWI Y ESKLI GDCP THYVTRELP-S--I YSPSTVLEAVCACGGSQC - -SELHENYIDPEVLLYPEWIYESKLI GDCPTHYRTRELP-P--KYSPA IVLEAECACRESQC - TDLHKNH I TPELQLHPEWI H TSQLI GTCPTHYVTRELP-P--MYSPSVVVEAVCTCTGSKC - -VDLH KNHVKP ELQLRPNWI HKSEFI GDCP TNYVARELP-P--MYSPTVILEAVCACGGSQC - -SNLHENH I KPELQLRPDWI H ISELI GDCPTHYVARDLP-P--MYSPAVVLEAVCTCGGSQC - SNLHENH I KP ELQLRPDWIH ISELI GDCP THYITRELP-P--MYSPAVVLEAVCTCGGSQC --VPLF RVDMRH H - YVEPRWMRN T LDVGVCPS I L QEKRLGE-- -NVWPP SVVEVRCLC QQQSC --VQLFEVDLWEE-DLKPLWVRKTVHL GVCP SMLQERRL GN---DVWP SRVVEVKCLCQQQSC --VQLFAVDLREH-NLEPMWVRETVYL GVCPSMLQERRLGE---HVWPS SVVEVKCLCQRASC --VQLFRVDLSEH-YLEPVWVKE IVHL GMCPSKLQTRSF GK---DVWPSTIVEAKCLCNNQPC --VQLFRVDLSED-YLEPLWVRGTVHLGMCPSKLQTRHLGE---NVWP P N IVTKCLCQGETC --VQLFRVDLTEH-HLEPLWVRDSVHLGVCPSKLQTRHLGD---KVWPSKVVEVKCLCQRESC - -VDKVSIELDSHQELIPTWLRDATLIGECPWQLVKRKLDD-- -DMVPPE ILEVNCLCNGFRC - LDAQGMP QRDY S GY QP QWLEDATTAGDCPWH LVRKEFMH---GTLPAA I LEVSCLCDGLRC - GSAQKVQLQDY SGF RPHWLVDATTAGE CPWHMG----

SQD--GS ICVAVKYRLPVWI SVD-SDG--YTTDTVELAVACACAKNPSRDGGY IDL SENK SQD--GS I CVAVKYRLPVWI SMD-SDG--YTTDTVELAVACACAKNP SRDGGY IDLSENK ADD--GSVCVALKYRLPVWIKLD-SKD--YTTDTVELTVACACAKNP SREGGYTNIGENY SQD--GS I CVAVKYRLPVWIRVD-SDG--YTTDTVELTVACACAKNP SRDGGYVDLSEN SQD--GYRCEPLKYNMLVWKFDSF SNR--SF SEYVYLTVACVCARRPSSIAGSSETLGEPS SED--GHQCVPVSRHVPVWVRRG-PNL--HVLDVEELTVACACARRP SAGGNF IF SAAVES SRS--GHQCVPVSRHVPVWVRRG-PNL--HVLDVEELTVACACARRP SAGGNF IF SAAVES SRD--GHQCLPVSRH IPVWVRQG-PNF--HVLDVEELTVACACVRRP SVGGNF I FASAVHSK SRR--GHQCVPVSSRVPVWVRRG-PNF--LVLDVEELTVACACVRRP SGEGNF IFEAAVQS SRD--GHQCVPVTRH IPVWVRRG-PNI--HVLDVEELAVACACVRRP SVGGNFVF SPAVHS SRD--GHQCVPVTXHIPVWVRRG-PNV--HVLDVEE-

SDRGWDFRCQAVQQTIMTWVRQS-SQD--FMP STEVVSVGCMCAQRTGTEGRVANMVES SSF GGDF RCQAVRRSVRTWVRSS-EKT--FVP SQEIVSVGCVCVPRTSTP-----------SKKGGDFRCQAVRRTVQTWVRHG-SQT--FVPSQETVSVGCVCVQRTGTEANHVSLRER SNLGGDFRCQAVRKP IRTWVRHV-E-K--FMPVQEMVTVGCVCVQRTSP EGKYARPA IEA SNLGGDF RCQAVRRP I RMWVRHL-D-Q--F I P TQEMVSVGCVCVQRISP GGNSANP S L S SNLGGGF RCQAVRRPVRMWVRHQ-D-S--F I P TQEMVSVGCVCVQRVSP GGKY I S P S LQS SE-GGLFKCTPVTQEVKMWRSST-SKSYLLQLDRIRVTIGCVCAQRHSPEÄGFVDHVE ID SV-QGDFRCT SVTRQVTVWS SEA-SGGAHYLPRYLEVTTACVCAQRHALQGGHVHPGP 
Figure $\mathbf{6}$ (on next page)

CFSH phylogenetic tree.

Phylogenetic tree of the various CFSH orthologs identified here and elsewhere. The only Scylla sequence is from S. olivacea (GDRN01022056.1). S. paramosain has a very limited number of SRA reads that correspond to three orthologs found in Carcinus and Eriocheir. Note that Macrobrachium, Litopenaeus and Procambarus seem to have independently gone through relatively recent gene duplications. 


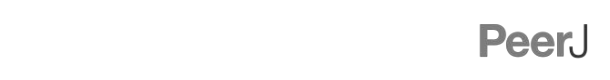


Figure 7 (on next page)

Configuration of Eriocheir neuroparsin genes 3 and 4 .

The relative organization of the two neuroparsin genes relative to one another is indicated. The two genes are located on opposite strands and each gene has four exons and three introns. Numbers indicate the lengths of the exons, introns and the intergenic distance in nucleotides. 
$\leftarrow$ Neuroparsin 4

Neuroparsin 3

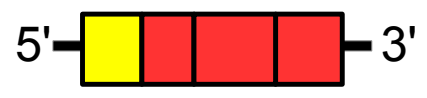

Neuroparsin 3

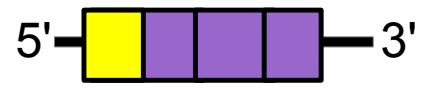

Neuroparsin 4 


\section{Figure 8 (on next page)}

Neuroparsin phylogenetic tree.

The different decapod neuroparsin sequences found in the different species were used to make a phylogenetic tree. Note that one neuroparsin gene duplication likely occurred after the crabs separated from the other decapods. 


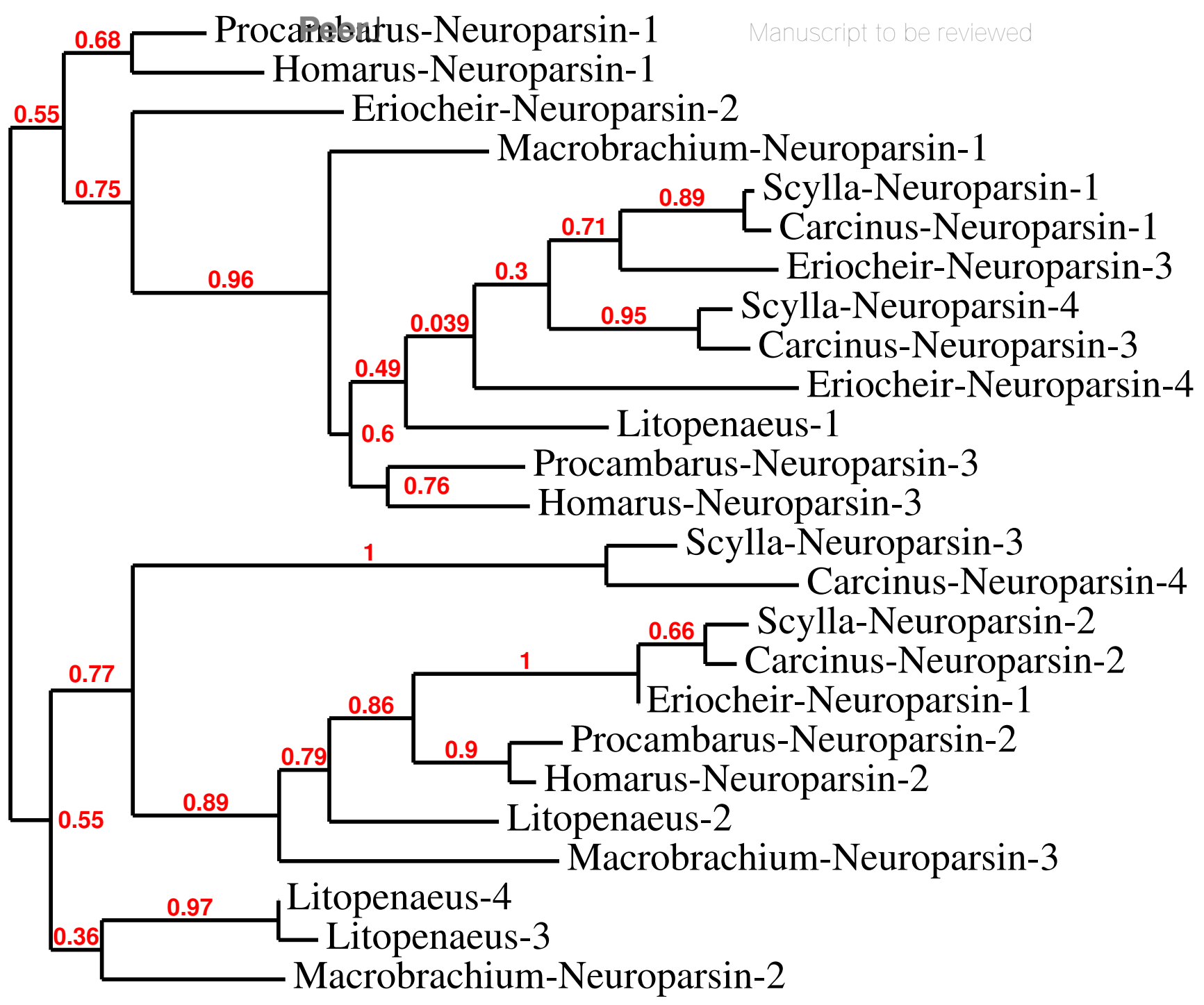

0.4 
Figure 9 (on next page)

Phylogenetic tree of the tyrosine kinase domains of the decapod insulin and venus kinase receptors.

Venus kinase receptors from the following species were added for increased resolution:

Limulus polyphemus, Stegodyphus mimosarum, Locusta migratoria, Ixodes ricinus and

Zootermopsis nevadensis. Note that the duplication of the venus kinase receptor gene is not generally present in arthropods and could thus be specific to crustaceans. 


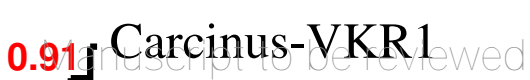

0.99 Scylla-VKR1

0.9 Eriocheir-VKR1

0.92 Homarus-VKR1 $14 \begin{aligned} & 0.92 \\ & {[0.32} \\ & 0.920 c a m b a r u s-V K R 1 \\ & \end{aligned}$

Lacrobrachium-VKR1

1

1

0.97

0.88

Carcinus-VKR2

0.96 - Scylla-VKR2

Eriocheir-VKR2

1 Homarus-VKR2

0.91 O.83rocambarus-VKR2

0.76 Litopenaeus-VKR2

0.76 Macrobrachium-VKR2

0.87

0.99 - Locusta-VKR

Zootermopsis-VKR

Stegodyphus-VKR

0.990 .91 Limulus-VKR

— Ixodes_ricinus-VKR

Strigamia-VKR

$\begin{array}{cc}0.95 & \text { Homarus-InsR } \\ & \text { Procambarus-InsR }\end{array}$

$1 \quad$ Litopenaeus-InsR

Macrobrachium-InsR 
10

Sequence alignment of the decapod adrogenic insulin-like peptides.

Note the relatively poor conservation of the primary sequences of these hormones.

Conserved residues indicated in black highlighting, and cysteine residues in red.

Eriocheir Callinectes Scylla

Procambarus Litopenaeus Macrobrachium

Eriocheir Callinectes scylla

Procambarus Litopenaeus Macrobrachium

Eriocheir Callinectes Scylla

Procambarus Litopenaeus Macrobrachium

Eriocheir Callinectes Scylla

Procambarus Litopenaeus Macrobrachium
MSLPSVL-------LLMLLTATATRA--QDCSFSVDCANLLDSMNTVCRSYKQHPGYRR MCPRVIL------ILVLLTATQTKA-DLISDFSVDCGNLLRSFSSVCLTYKQSLSERY MLTQTLLKLILQVLVAVLRSLPSSSYWVDNLLVDFDCGNLADTMDSICLTFNEYNDTHL $=---------------------------------G D T M S Q I$ CKTF P T ARP HVMGYWNAE IKCVLFCSLVASLLPQPSSSYE IECLSVDFDCGDITNTLASVCLRHNNY INPGP

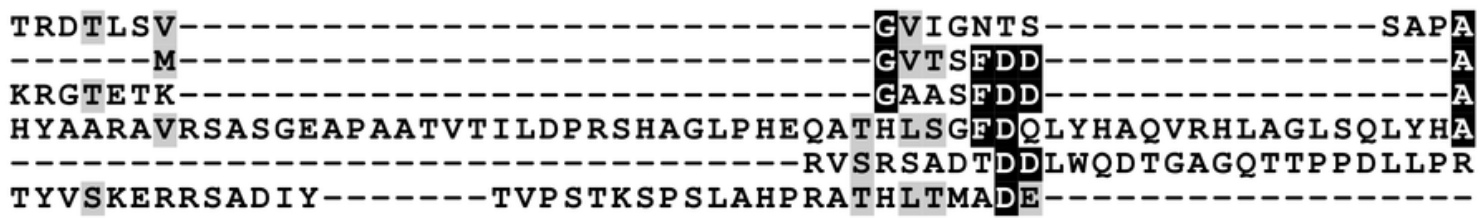

YTALQP------ PAAAVEMLDEENPMLPPQVAARVF QMDRVGGRF---RRSERTVDAYTQ NTDFRPQ------PLHALSVEQGEDPMLPP ENAF QLFTTQẄAGGRF---RRSSRYVNGYDE TTEFRPR------PLHVLLAEQDEDPMLP EDAF QLVKTHWTRERE---RRSHRYVNGYDE QARH HPAED I T LVDQVSTD-EDRKMALLSRQAAH TFVKTQTRRHRRQANTDNHVRFNI QDE RHRL HPRA - - LNPTWNLERDL I KDI LVSPEAAHALVRTPR- - - - - -SRAKRS YNVQDE - - - - - - - ET-QKVSKVEGE I QHMTLSREEANNML H SRRF- - - - -RRDSVRRSPREE

CCV----ENCTLHEVAGYCETFQPEYQFLATGNPCA CCPQ-STKSCSVYEVAEYCDTLRPPYRELLASRNSQ CCPQ-STKNCTVYEVAEYCDSLRPPYRELLASRKRQ CCNYMRPRTCVLEEITEYCVEPEDGALLTW CCNHVSQRMCVAEEILEYCEDPVP

CCNNASFRRCNFEEVAEYCIELRPGVNTCSSR 
Sequence alignment of the decapod insulin-like peptides.

Note the much better conservation of the primary sequences of the $A$ and $B$ chains of these hormones. Conserved residues indicated in black highlighting, and cysteine residues in red. The Carcinius sequence, although incomplete, is clearly part of an insulin precursor.

Conserved residues indicated in black highlighting, and cysteine residues in red.

\begin{tabular}{|c|c|}
\hline $\begin{array}{l}\text { Procambarus } \\
\text { Homarus } \\
\text { Litopenaeus } \\
\text { Macrobrachium } \\
\text { Eriocheir } \\
\text { Scylla } \\
\text { Carcinus }\end{array}$ & 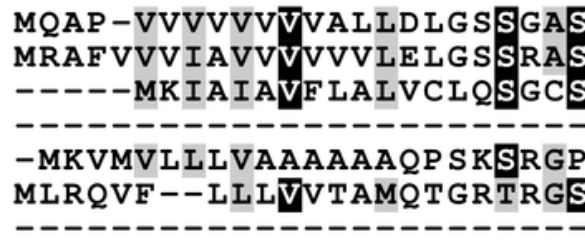 \\
\hline $\begin{array}{l}\text { Procambarus } \\
\text { Homarus } \\
\text { Litopenaeus } \\
\text { Macrobrachium } \\
\text { Eriocheir } \\
\text { Scylla } \\
\text { Carcinus }\end{array}$ & 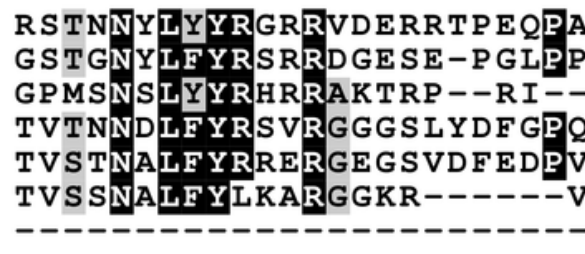 \\
\hline $\begin{array}{l}\text { Procambarus } \\
\text { Homarus } \\
\text { Litopenaeus } \\
\text { Macrobrachium } \\
\text { Eriocheir } \\
\text { Scylla } \\
\text { Carcinus }\end{array}$ & $\begin{array}{l}\text { VSRGPAYDSRDP } \\
\text { EAPGSFFGSLSP } \\
---G-------- \\
---D S Y Y Y---Y \\
------------ \\
------------ \\
-----------\end{array}$ \\
\hline $\begin{array}{l}\text { Procambarus } \\
\text { Homarus } \\
\text { Litopenaeus } \\
\text { Macrobrachium } \\
\text { Eriocheir } \\
\text { Scylla } \\
\text { Carcinus }\end{array}$ & $\begin{array}{l}\text { KRGLSAECCQKVCTVSELVGYCY } \\
\text { KRGLSAECCRKVCTVSELVGYCY } \\
\text { KRGLSAECCRKACSVSELVDYCY } \\
\text { KRGLSAECCRKACRVSELMGYCQ } \\
\text { KRGLSAECCRKACTVSELAGYCY } \\
\text { KRGLSAECCRKACSVSELAGYCY } \\
\text { KRGLSAECCRKACSVSELAGYCY }\end{array}$ \\
\hline
\end{tabular}


Sequence alignment of the decapod relaxins.

Note the relatively good sequences conservation between the different decapod peptides and Dilp-7. Conserved residues indicated in black highlighting, and cysteine residues in red.

Dilp-7

Litopenaeus

Macrobrachium

Homarus

Cherax

Procambarus

Sagmariasus

Dilp-7

Litopenaeus

Macrobrachium

Homarus

Cherax

Procambarus

Sagmariasus

Dilp-7

Litopenaeus

Macrobrachium

Homarus

Cherax

Procambarus

Sagmariasus

Dilp-7

Litopenaeus

Macrobrachium

Homarus

Cherax

Procambarus

Sagmariasus
MTRMI IQNSGSWT LCGAVLLFVLP L I P PEALQHTEEGLEMLF RERSQSDW̄ENVฟ̄QET HS MVMSMMLAVF L LCSTSLALDP DFVRQIESRTELEWQALWSEERLA - - - MVVVIAAI LVVVS TSWALEPYLIRQLQSRTEAEWEVLWNKERLA

MLALTAMFVLGSTSWALESDLIRQIESRTETEWQTLWSKERLS MMALILAAMFVIAA ISWALDPDLIRQIESRTEAEWQTLWSKERLA MLAADMVVLVLAAMLTLVTFSWALEPDLISQIESRTEKEWQELWTEERLT

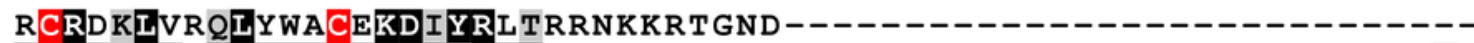

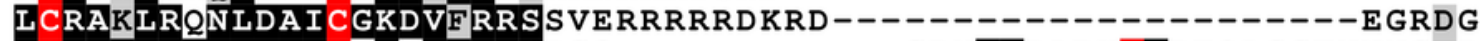
LCRARLRHNLDA I CSKAVYRRSPGQ-----------GRYKRRAPKCLRT QAGG TNNNGED LCRARLRHNLEA I C GKDVYRRS I TPPNH-H-------H IKRSTDTCLKVHD GD GE R---LCRARLRHNLDTI C GKDVYRRSLAP PRP AP-----YHH I FKRRTDICLQVHDT GGARRVEG LCRARLRYNLDSICGKDVYRRSIKTPP P SHHQHQKQH HLVKRTTDICVHVHEAGGE SAEDN LCRSRLRHNLDA I CGKDVYRRSSMLPPRTRHR---RWSRAKRNTDIF FEVHDTDTARGDSR

E-------------------AWIKKTTTE--------------PDGSTWLHVNYANM SKP LP------------AE SDEVPRANPSTPDTGQAPD-------KRRSPF LSVQQANL - - - - - NRG T TNANAVMTYPP S S TDVRP SLPDTGQNAE-------E GRSP F LSVQQANL $---------D V R D K R A V S V N L P T A T T E I T P S S P D T G Q H N I-------N T R S P F L S V H Q A N L$ EKHLSKS SNRVKRVREVLVNLSPDII ITSP-ATDTGQP SVQDRHVHSRYRSPF LSVHQANI T------EKRE KS LD GAE S ILPS T T IE INP STPDTGQE SV-------QARSP F LSVHQANL $-------K K E K R M K T M S V D L P T T R I E$ I SP SVPDTGOH ST-------H TRSP F LSVHQANL

FLRSRR-------------SDGNTPSISNECCTKAGCTWEEYAEYCPSNKRRNHY FVTTWVHDQGGRRRGRS HYRRRRQSP S ITTECCTVAGCTWEEYAEYCP SSNRARF L FVTTWVRGG-----GPVHGRRRRQS SS I TSECCTAAGCTWEEYAEYCPT S SRVRP GVI PI FVTTWVGGR-----RGSHYRRRRQSS I TAECCTTVGCTWEEYAEYCP TSSRLRP GVTP I FVT TWVRDH-----QGRHYRRRRQSSS I TAECCTT TGCTWEEYAEYCP T SSRLRAGVALI FVT TWVGGRG---RRGPQHRLRRQSP S I TAECCTAVGCTWEEYAEYCP T S SRLRAGVT I I FVTTWVGGH--------HRHRRQSP S I TSECCTTVGCTWEEYAEYCP T S SRLRP GVT LI 
Figure 13(on next page)

\section{Last parts of CNMamide precursors}

Some arthropods produce alternatively spliced mRNA predicted to produce different CNMamides. Notice that the major splice variants produce a much better conserved neuropeptide than the alternative ones. Residues in red are predicted to be cleaved by convertase and removed by carboxypeptidase during processing; the green glycine residues will be transformed in C-terminal amides and the cysteine residues are orange. Residues conserved between the different species are in blue. 
Species

Scylla

Eriocheir

Carcinus

Homarus

Litopenaeus

Macrobrachium

Procambarus

Zootermopsis

Drosophila splice variant 1

splice variant 2

KRVMCHFKICNMGRRRRARHSNPLQGWLS KRVMCHFKICNMGRRRRARHSSPVQGWLS KRVMCHFKICNMGRRRRARHSNPLQGWLS KRVMCHFKICNLGRRRRARQSSPLQGWLS KRVMCHFKICNLGRRRRARQSLPLQGWLS KRVMCHFKICNLGRRRRARMS KRVMCHFKICNLGRRRRARQSSPLQGWLS KRGNYMSLCHFKICNMGRKRNFRWNPWIRR KKNVQYMSPCHFKICNMGRKRNAGFNSY

\section{KRERKWYCGLWMAICPFSG} KRGRKWHCGLWMPICPFSG

KREADAPSITQKKRPCILYLRICPFRSLR

KREAIWPCVLWVKFCPLG

KRGNYPPPLCY FKICNMGRKRNPH 
Sequence alignment of the decapod B-calcitonins.

Some of the decapod B-calcitonins are predicted to have two cysteine bridges in the N-

terminal part of their sequence, rather than one.

Procambarus

Macrobrachium

Litopenaeus

Eriocheir

Carcinus

Procambarus

Macrobrachium

Litopenaeus

Eriocheir

Carcinus

Procambarus

Macrobrachium

Litopenaeus

Eriocheir

Carcinus
MRMACCWWLVCSAFIVLAAVAGP S L GQPIQ-DSDLGDMP ERLRELLLIRRLV MRQGCWVACF SLIAMVAAAF SAHVQPVP -ESDVGE IP ERLRELLLVRRLI MSRTANLMFTVLLGLIGLTLSAHVQPIQ-ESELSSVPERLREFLIIRRLI MIVSVAMCVFLVCVGAG--- AQPVHE--NENYLNDNLREYLLLKRLF MRLVVIVLCLMLLWCVGVG-- - AQPTH HESQEAYLSEKMREYLLLRRLL

SNLNSAEAA I P D - - AL - - P G I RGQ S Y LE HELEQLAKASAAA IDFRGIRVSRR SSLNPAEALPEL--QAQP AQA I S YNLKKDLETLSKAAAAD IDFRALRVSKR NNLKVVEAGHEI PAAVEDPSRI---RLEHELQMLAKALEADMDEEDLHVSTR VNIFGRESELAP-- IP----

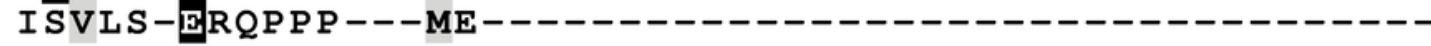

AIRSYCSTN-P DRQCRSFCFNLGDAACAEGDIGGNGEDSHF LASGNTPGK SIRSFCSSNNSNRQCRSFCFNLGDSACADGDLGGNGEDSKF LSGGLTPGK AVRSFCAGN-GSRQCRSFCFNLGDRACSDGDIGGNGEDSHFIESGMNPGK $------------A P S K K M C L N L G D P S C Y H G N V N G N G E D S N Y I S S G Y N P$ GK $-----------A P R K R$ CLNLGDP SCYEGNMAANGDDNNYLIGQNNP GK 
15

Hyrg sequence alignment.

Note that only a small part of the sequence of this puative neuropeptide is conserved in both decapods as well as in Euphausia crystallorophias.

Euphasia_1

Euphasia_2

Eriocheir

Scylla

Carcinus

Homarus

pontastacus

Procambarus

Macrobrachium

Marsupenaeus

Litopenaeus

penaeus

Euphasia_1

Euphasia_2

Eriocheir

Scylla

Carcinus

Homarus

Pontastacus

Procambarus

Macrobrachium

Marsupenaeus

Litopenaeus
MNTVQVVGLMVMAL-VAF S GALPTPDEDMTYVP T F P I SP MNTVQVVGLMVMAL-VAF S GALPTP DEDMTYVP T F Y I SP MK I L H LLMVVAAA-VGRVVAQQKPGLVLDDP - - - - - MNI LSI LIIIVAAA - AASVMAQQKPT IILED P - - - - - MNIFNIIIIV-IAA-VVSVMAQQKPR I LIED P - - - - - MNLVSMLVIVMAAL - LAPVS SLPEP DVLIDRA - - - - - MNLVSVLVIMMAAL LWAP A L S PDAEVLMEAE-- - - - MNLVSVLMLVMAALILAP S H S PDAEVLMEVA-- - - - MNLFSLIIVIVAAI-IGITQGLPEPAVIVDGR-- - - - VDHASGYDISTSGRSVAAM-FGTAHSIPEPDPLAEAG--- - - - MNLLH LIVVV IAAM - I GS S HALPEP DP MAEAG- - - - - -

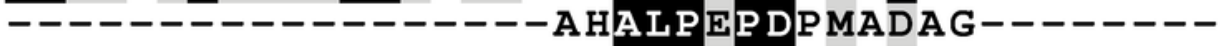

EQD LRS YVEEYAP PRI I R G GQKAPPARFHYRGFQRAG - - NDẄGQ EQDLRSYVE-YA-------------P PRFHYRGFQRAG- NTWGQ

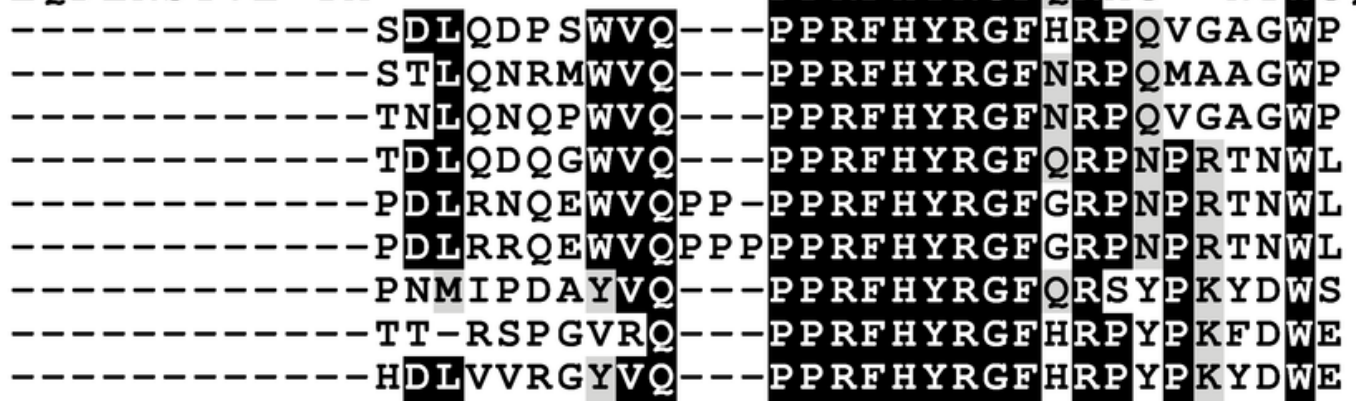


Figure 16 (on next page)

Ligand-receptor interactions of insulin-related peptides.

Figure indicates the postulated major interactions of the three decapod insulin-like peptides with three receptors. Secondary interactions are indicated by broken lines. Drosophila gene numbers for orthologous genes are indicated in red. LRR-GPCRs: Leucine-riche repeat GPCRs. 
Insulin Dilps 1-6 Relaxin Androgenin Dilp-8
Tyrosine Kinase

LGR4 CG34411 LGR3

LRR-GPCRs CG31096 


\section{Table $\mathbf{1}$ (on next page)}

Tissue distribution of neuropeptides and neuropeptide GPCRs in various tissues of Carcinus maenas. Part 1.

The number of individual reads found in different SRAs from cDNA prepared from eggs and eleven tissues of Carcinus maenas. Note that the numbers refer to the individual reads corresponding to each gene that are present in each of the twelve SRAs. These numbers are not normalized and as the preparation of CDNA libraries includes a PCR step, such numbers are not a reliable reflection of the expression level of the genes of interest. 


\begin{tabular}{|c|c|c|c|c|c|c|c|c|c|c|c|}
\hline $\begin{array}{l}\text { g } \\
\text { 号 }\end{array}$ & $\stackrel{\bigotimes}{\amalg}^{\otimes}$ & 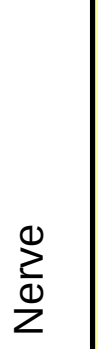 & 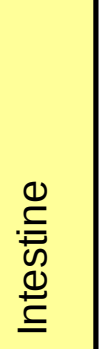 & $\begin{array}{l}\frac{\lambda}{\sqrt{0}} \\
\text { రి }\end{array}$ & $\begin{array}{l}\stackrel{\mathscr{N}}{\mathscr{N}} \\
\stackrel{\mathscr{E}}{=}\end{array}$ & 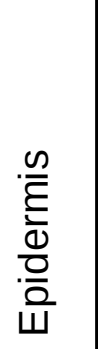 & $\begin{array}{l}\frac{\bigcup}{U} \\
\stackrel{\mathscr{N}}{D} \\
\sum\end{array}$ & $\begin{array}{l}\frac{ \pm}{\widetilde{J}} \\
\stackrel{\Theta}{I}\end{array}$ & $\begin{array}{l}\mathscr{N} \\
\mathbb{d} \\
\frac{1}{U} \\
\frac{1}{\pi} \\
\frac{0}{0} \\
\frac{0}{\pi} \\
\frac{0}{d} \\
I\end{array}$ & $\overline{\overline{0}}$ & 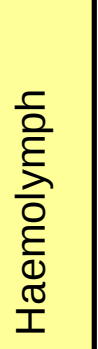 \\
\hline 17 & 87 & 1 & 0 & 24 & 0 & 2 & 0 & 0 & 0 & 0 & 4 \\
\hline 6 & 11 & 1 & 1 & 0 & 0 & 1 & 0 & 0 & 0 & 2 & 0 \\
\hline 119 & 823 & 1376 & 2 & 2 & 0 & 1 & 0 & 6 & 2 & 0 & 0 \\
\hline 35 & 138 & 1093 & 1 & 1 & 3 & 4 & 1 & 0 & 2 & 1 & 83 \\
\hline 14 & 45 & 115 & 12 & 11 & 1 & 42 & 143 & 25 & 2 & 1 & 0 \\
\hline 85 & 272 & 387 & 0 & 165 & 1 & 8 & 1 & 2 & 0 & 2 & 0 \\
\hline 8 & 5 & 37 & 8 & 27 & 3 & 27 & 3 & 0 & 29 & 7 & 4 \\
\hline 31 & 41 & 331 & 246 & 7 & 0 & 26 & 0 & 3 & 3 & 0 & 0 \\
\hline 19 & 1 & 155 & 2 & 0 & 1 & 1 & 0 & 0 & 0 & 0 & 0 \\
\hline 7 & 46 & 76 & 0 & 53 & 0 & 3 & 0 & 0 & 0 & 1 & 1 \\
\hline 19 & 17 & 10 & 2 & 105 & 4 & 86 & 1 & 0 & 0 & 0 & 0 \\
\hline 16 & 12 & 10 & 2 & 104 & 4 & 88 & 1 & 0 & 0 & 0 & 0 \\
\hline 14 & 0 & 550 & 0 & 16 & 0 & 7 & 0 & 0 & 0 & 0 & 0 \\
\hline 10 & 0 & 444 & 2 & 0 & 0 & 0 & 0 & 0 & 0 & 0 & 0 \\
\hline 202 & 59 & 98 & 46 & 31 & 20 & 49 & 91 & 51 & 3 & 65 & 0 \\
\hline 24 & 12 & 11 & 178 & 0 & 0 & 0 & 0 & 0 & 0 & 0 & 0 \\
\hline 17 & 10 & 10 & 112 & 0 & 0 & 0 & 0 & 0 & 0 & 0 & 0 \\
\hline 2 & 1 & 5 & 2 & 0 & 0 & 0 & 0 & 0 & 0 & 0 & 0 \\
\hline 18 & 10 & 1 & 121 & 0 & 0 & 0 & 0 & 0 & 0 & 0 & 0 \\
\hline 3 & 8 & 38 & 0 & 0 & 0 & 0 & 0 & 0 & 0 & 1 & 0 \\
\hline 3 & 12 & 13 & 1 & 1 & 0 & 0 & 1 & 1 & 0 & 2 & 17 \\
\hline 3 & 3 & 4 & 8 & 22 & 3 & 9 & 0 & 0 & 0 & 0 & 0 \\
\hline 7 & 2 & 9 & 0 & 25 & 126 & 7 & 0 & 0 & 0 & 0 & 0 \\
\hline 2 & 23 & 34 & 0 & 112 & 0 & 20 & 0 & 0 & 0 & 0 & 0 \\
\hline 0 & 5 & 6 & 0 & 40 & 0 & 3 & 0 & 0 & 0 & 0 & 0 \\
\hline 0 & 0 & 0 & 0 & 17 & 0 & 1 & 0 & 0 & 0 & 0 & 0 \\
\hline 20 & 153 & 4 & 0 & 0 & 0 & 0 & 0 & 0 & 0 & 0 & 0 \\
\hline 26 & 89 & 208 & 0 & 0 & 1 & 0 & 0 & 106 & 0 & 0 & 0 \\
\hline 10 & 6 & 9 & 0 & 0 & 0 & 0 & 0 & 1 & 0 & 0 & 0 \\
\hline 34 & 31 & 823 & 0 & 0 & 0 & 0 & 0 & 1 & 0 & 0 & 0 \\
\hline 22 & 3 & 23 & 6 & 25 & 1 & 11 & 14 & 9 & 2 & 1 & 0 \\
\hline 15 & 3 & 25 & 5 & 18 & 0 & 11 & 15 & 9 & 2 & 2 & 0 \\
\hline 1 & 353 & 0 & 0 & 0 & 0 & 2 & 0 & 0 & 0 & 0 & 0 \\
\hline 1 & 23 & 1 & 0 & 1 & 0 & 0 & 0 & 0 & 0 & 0 & 0 \\
\hline 0 & 1 & 0 & 0 & 2 & 0 & 1 & 0 & 0 & 0 & 0 & 0 \\
\hline 83 & 3418 & 476 & 101 & 78 & 25 & 46 & 26 & 28 & 14 & 61 & 4 \\
\hline 111 & 4969 & 663 & 141 & 125 & 35 & 59 & 47 & 33 & 18 & 80 & 7 \\
\hline 24 & 366 & 330 & 2757 & 44 & 49 & 41 & 4 & 20 & 45 & 18 & 2 \\
\hline 43 & 173 & 735 & 1 & 2 & 0 & 0 & 0 & 4 & 0 & 0 & 0 \\
\hline 11 & 161 & 28 & 0 & 0 & 6 & 1 & 0 & 0 & 0 & 0 & 0 \\
\hline 10 & 0 & 0 & 0 & 0 & 0 & 1 & 0 & 0 & 0 & 0 & 0 \\
\hline 103 & 48 & 120 & 1 & 3 & 5 & 50 & 0 & 1 & 0 & 0 & 0 \\
\hline 11 & 30 & 45 & 0 & 0 & 0 & 0 & 0 & 0 & 0 & 0 & 0 \\
\hline 15 & 7 & 10 & 0 & 0 & 1 & 10 & 0 & 0 & 0 & 0 & 0 \\
\hline 5 & 12 & 32 & 156 & 0 & 4 & 3 & 0 & 0 & 2 & 0 & 1 \\
\hline 5 & 8 & 6 & 81 & 1 & 0 & 4 & 0 & 1 & 3 & 4 & 4 \\
\hline 14 & 75 & 84 & 36 & 78 & 57 & 92 & 67 & 43 & 28 & 24 & 25 \\
\hline 33 & 233 & 121 & मि & & & $=34$ & & 1 & 0 & 0 & 0 \\
\hline 3 & 19 & 51 & 2 & 4 & 2 & 81 & 41 & 49 & 3 & 25 & \\
\hline
\end{tabular}

ACP

ACP-GPCR

Agatoxin-like peptide

Allatostatin A

AstA-GPCR

Allatostatin B (= mip)

AstB-GPCR

Allatostatin $C$

Allatostatin CC

Allatostatin CCC

AstC-GPCR

AstC-GPCR, splice variant

Bursicon-A

Bursicon-B

Bursicon-GPCR

Calcitonin

Calcitonin common exon

Calcitonin A-specific

Calcitonin B-specific

CCHamide 1

CCHamide 2

CCHamide-GPCR-1

CCHamide-GPCR-2

CNMamide

CNMa a specific

CNMa b specific

Corazonin

CRF-like diuretic hormone

CRF-like DH-GPCR

CCAP

CCAP-GPCRa

CCAP-GPCRb

CFSH 1

$\mathrm{CFSH} 2 \mathrm{a}$

$\mathrm{CFSH} 2 \mathrm{~b}$

$\mathrm{CHH} 1$

$\mathrm{CHH} 1$ alternative splice product

$\mathrm{CHH} 2$

$\mathrm{DH} 31$

Eclosion hormone 1

Eclosion hormone 2

ETH

EFLamide

EFLamide-GPCR

Elevenin

Elevenin-GPCR-1

Elevenin-GPCR-2

FMRFamide

FMRFa-GPCR 


\section{Table 2 (on next page)}

Tissue distribution of neuropeptides and neuropeptide GPCRs in various tissues. Part 2.

The number of individual reads found in different SRAs from eggs and eleven tissues or Carcinus maenas. 


\begin{tabular}{|c|c|c|c|c|c|c|c|c|c|c|c|}
\hline $\begin{array}{l}\text { n } \\
\text { 号 }\end{array}$ & 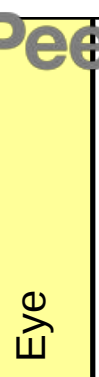 & $\frac{\sum_{0}^{\infty}}{Z}$ & 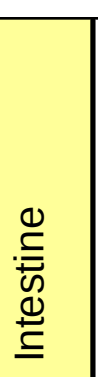 & $\begin{array}{l}\text { ते } \\
\text { రิ }\end{array}$ & 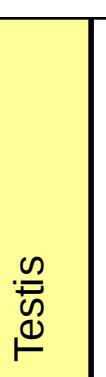 & 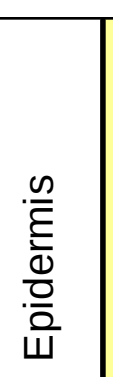 & 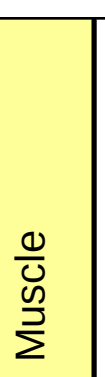 & $\begin{array}{l}\frac{\pi}{\widetilde{J}} \\
\stackrel{\mathbb{1}}{I}\end{array}$ & 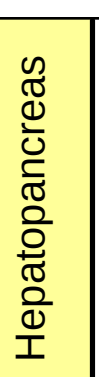 & Mal & $\begin{array}{l}\text { USC } \\
\frac{c}{\circ} \\
\bar{E} \\
\frac{\lambda}{O} \\
\frac{E}{\Phi} \\
\frac{\sigma}{I}\end{array}$ \\
\hline 12 & 46 & 43 & 0 & 0 & 0 & 1 & 0 & 0 & 0 & 0 & 0 \\
\hline 20 & 48 & 75 & 2 & 5 & 0 & 2 & 0 & 1 & 1 & 0 & 0 \\
\hline 80 & 216 & 788 & 45 & 41 & 7 & 64 & 36 & 80 & 0 & 1065 & 2 \\
\hline 1 & 571 & 3 & 30 & 0 & 12 & 1 & 1 & 0 & 2 & 0 & 1 \\
\hline 3 & 1 & 0 & 0 & 0 & 0 & 2 & 0 & 0 & 0 & 0 & 0 \\
\hline 26 & 29 & 22 & 16 & 150 & 13 & 57 & 4 & 3 & 2 & 3 & 0 \\
\hline 11 & 71 & 141 & 0 & 2 & 0 & 0 & 0 & 0 & 1 & 0 & 0 \\
\hline 11 & 120 & 228 & 0 & 0 & 0 & 0 & 0 & 0 & 1 & 0 & 0 \\
\hline 2 & 8 & 16 & 1 & 9 & 0 & 3 & 0 & 0 & 0 & 0 & 0 \\
\hline 4 & 189 & 0 & 0 & 0 & 0 & 3 & 0 & 0 & 0 & 0 & 0 \\
\hline 26 & 149 & 298 & 1 & 1 & 1 & 1 & 0 & 0 & 0 & 0 & 0 \\
\hline 39 & 13 & 45 & 133 & 18 & 0 & 7 & 6 & 2 & 0 & 4 & 0 \\
\hline 28 & 87 & 81 & 0 & 0 & 0 & 5 & 0 & 0 & 0 & 0 & 0 \\
\hline 130 & 952 & 4536 & 635 & 324 & 491 & 365 & 331 & 1444 & 161 & 1935 & 0 \\
\hline 73 & 182 & 478 & 13 & 22 & 0 & 6 & 4 & 8 & 0 & 6 & 0 \\
\hline 2 & 83 & 160 & 94 & 52 & 6 & 5 & 22 & 12 & 0 & 81 & 0 \\
\hline 308 & 94 & 877 & 108 & 402 & 124 & 665 & 2910 & 986 & 928 & 727 & 5 \\
\hline 357 & 258 & 1211 & 233 & 233 & 115 & 257 & 1119 & 519 & 131 & 199 & 17 \\
\hline 5 & 28 & 15 & 0 & 0 & 0 & 2 & 1 & 2 & 0 & 1 & 1 \\
\hline 3 & 22 & 12 & 0 & 0 & 0 & 2 & 1 & 2 & 0 & 1 & 1 \\
\hline 1 & 1 & 5 & 0 & 0 & 0 & 0 & 0 & 0 & 0 & 0 & 0 \\
\hline 20 & 62 & 45 & 0 & 1 & 3 & 0 & 0 & 0 & 0 & 3 & 0 \\
\hline 50 & 603 & 449 & 8 & 0 & 0 & 10 & 0 & 0 & 0 & 0 & 1 \\
\hline 40 & 223 & 661 & 26 & 0 & 0 & 2 & 0 & 0 & 1 & 0 & 0 \\
\hline 8 & 5 & 20 & 1 & 1 & 2 & 3 & 0 & 0 & 0 & 1 & 0 \\
\hline 112 & 446 & 2 & 1 & 2 & 4 & 5 & 3 & 3 & 0 & 4 & 2 \\
\hline 25 & 101 & 0 & 0 & 1 & 1 & 0 & 0 & 0 & 0 & 0 & 0 \\
\hline 26 & 7 & 3 & 1 & 0 & 1 & 1 & 0 & 0 & 0 & 0 & 0 \\
\hline 16 & 18 & 3 & 1 & 0 & 0 & 1 & 0 & 0 & 0 & 0 & 0 \\
\hline 17 & 91 & 411 & 0 & 0 & 1 & 1 & 0 & 0 & 0 & 1 & 0 \\
\hline 6 & 20 & 107 & 6 & 13 & 2 & 19 & 94 & 43 & 3 & 15 & 0 \\
\hline 12 & 18 & 119 & 0 & 7 & 1 & 10 & 0 & 3 & 0 & 0 & 0 \\
\hline 25 & 70 & 94 & 0 & 12 & 0 & 0 & 0 & 0 & 0 & 0 & 0 \\
\hline 2 & 2 & 6 & 0 & 2 & 0 & 28 & 0 & 0 & 0 & 0 & 0 \\
\hline 42 & 182 & 65 & 0 & 0 & 0 & 2 & 0 & 0 & 0 & 0 & 0 \\
\hline 93 & 2 & 103 & 0 & 0 & 0 & 0 & 0 & 0 & 0 & 0 & 0 \\
\hline 4 & 5 & 5 & 8 & 2 & 0 & 2 & 0 & 0 & 8 & 0 & 0 \\
\hline 5 & 8 & 7 & 9 & 3 & 0 & 35 & 0 & 0 & 146 & 0 & 0 \\
\hline 3 & 26 & 19 & 2 & 10 & 1 & 6 & 0 & 0 & 0 & 0 & 0 \\
\hline 5 & 1 & 20 & 1 & 0 & 3 & 79 & 0 & 0 & 2 & 0 & 0 \\
\hline 1 & 0 & 7 & 0 & 0 & 0 & 6 & 0 & 1 & 1 & 0 & 0 \\
\hline 44 & 410 & 395 & 0 & 0 & 0 & 1 & 0 & 0 & 0 & 1 & 1 \\
\hline 3 & 6 & 5 & 4 & 0 & 6 & 1 & 0 & 0 & 0 & 0 & 0 \\
\hline 30 & 296 & 124 & 246 & 3 & 0 & 0 & 2 & 2 & 0 & 0 & 0 \\
\hline 8 & 12 & 31 & 9 & \begin{tabular}{|l|}
18 \\
\end{tabular} & 1 & 45 & 4 & 4 & 5 & 8 & 169 \\
\hline 10 & 36 & 42 & 0 & 4 & 1 & 5 & 0 & 0 & 0 & 0 & 2 \\
\hline 4 & 3 & 2 & 0 & 0 & 0 & 11 & 0 & 0 & 0 & 1 & 0 \\
\hline 9 & 10 & 7 & 3 & 52 & 0 & 1 & 0 & 0 & 0 & 0 & 1 \\
\hline 1 & 2 & 0 & & 3 & ? & $w^{2}$ & 1 & 0 & 0 & 0 & 0 \\
\hline
\end{tabular}

GPA2

GPB5

GPA2/GPB5-GPCR

Hyrg

Insulin

Insulin tyrosine kinase receptor

Leucokinin-a

Leucokinin-b

Leucokinin-GPCR

$\mathrm{MIH}$

Myosuppressin

Myosuppressin-GPCR ?

Natalisin

Neuroparsin 1

Neuroparsin 2

Neuroparsin 3

Venus kinase receptor 1

Venus kinase receptor 2

Neuropeptide F 1a

Neuropeptide F 1b

NPF 1b specific

Neuropeptide F 2

Neuropeptide-like precursor 1

Orcokinin-A

Periviscerokinin

$\mathrm{PDH} 1$

$\mathrm{PDH} 2$

PDH-GPCR-1

PDH-GPCR-2

Proctolin

Proctolin-GPCR-1

Proctolin-GPCR-2

Pyrokinin

Pyrokinin-1-GPCR-2

$\mathrm{RPCH}$

RYamide

Ryamide-GPCR-1

Ryamide-GPCR-2

SNPF

SNPF-GPCR-1

SNPF-GPCR-2

SIFamide

Sulfakinin

Tachykinin

Trissin

Vasopressin

Vasopressin-GPCR

CG31096 ortholog

CG34411 ortholog 